

\section{DISCLAIMER}

This report was prepared as an account of work sponsored by an agency of the United States Government. Neither the United States Government nor any agency Thereof, nor any of their employees, makes any warranty, express or implied, or assumes any legal liability or responsibility for the accuracy, completeness, or usefulness of any information, apparatus, product, or process disclosed, or represents that its use would not infringe privately owned rights. Reference herein to any specific commercial product, process, or service by trade name, trademark, manufacturer, or otherwise does not necessarily constitute or imply its endorsement, recommendation, or favoring by the United States Government or any agency thereof. The views and opinions of authors expressed herein do not necessarily state or reflect those of the United States Government or any agency thereof. 


\section{DISCLAIMER}

Portions of this document may be illegible in electronic image products. Images are produced from the best available original document. 
NUS-217

\title{
CALCULATIONAL MODELS FOR BETA DOSE FROM SPHERICAL PARTICLES
}

\author{
For
}

Space Nuclear Propulsion Office

Atomic Energy Commission

National Aeronautics and Space Administration

By

George H. Anno

February 26, 1965

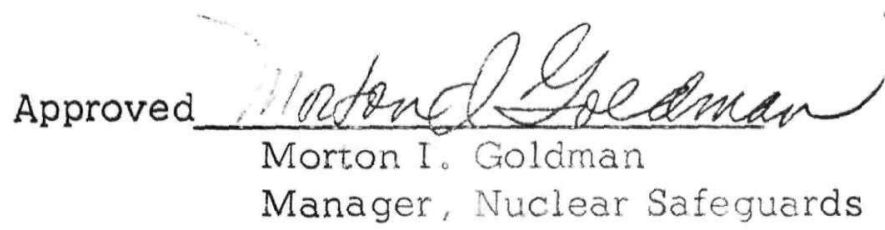


TABLE OF CONTENTS

\section{LIST OF FIGURES}

I. SUMMARY

II. INTRODUCTION

III. CALCULATIONAL MODELS

A. EXPONENTIAL MODELS .

1. Surface Dose

2. Dose Distribution

3. Integral and Average Dose

B. LINEAR MODEL

C. TRANSPORT MODEL

BIBLIOGRAPHY

APPENDIX 


\section{FIGURES}

1. Depth Dose in Tissue From ${ }^{89}$ Sr Spiked $1 \mathrm{~cm}$ Diameter Fuel Sphere (Dose Rate Averaged Over $1 \mathrm{~cm}^{2}$ Area)*

2. Ratio of Stopping Powers (Lead to Aluminum) From 0.01 Mev to $0.2 \mathrm{Mev}$

3. Ratio of Stopping Powers (Lead to Aluminum) From 0.2 Mev to $8.0 \mathrm{Mev}$

4. $\mathrm{Sr}^{89}$ Beta Ray Spectra Fractional Contribution vs Energy

5. Beta Ray Dose Calculational Model

6. Comparisons of $f(X)=4 \pi X^{2} J(X)$

7. $\mathrm{X} \mathrm{J}(\mathrm{X})$ Functions vs $\mathrm{X}$ for Material of $\mathrm{Z}_{\text {eff }}=32.5$

* See Reference number 2 


\section{SUMMARY}

A means of calculating the beta ray dose in tissue from a mixed radionuclide source particle of arbitrary size is considered for possible inclusion in the ROVER Flight Safety evaluation or NURSE(1) programs.

For the present case, the source particle is a high- $Z$ material $(Z \simeq 84)$ and contains a mixed beta ray spectra, while dose distribution in tissue, a low $-Z$ material $(Z \simeq 7)$, is desired: a situation for $w$ hich appropriate data is lacking. An investigation of the presently available techniques and data was carried out in order to (1) prescribe a method of computing the beta dose from a fuel particle for present use and also to (2) determine alternate methods to accomplish this task more accurately, perhaps by more detailed methods, if necessary in the future.

A current calculational model based on experimental dose attenuation of more monoenergetic beta ray sources was developed for which the equations can readily be translated to FORTRAN, (Appendix). Some hand calculations have been made in order to cornpare results with experimental data and results obtained by other methods. (2) These comparisons indicate good agreement with measured data for the particle surface leakage dose, and only approximate agreement for deeper penetration.

The exponential model described herein, however, does not explicitly treat electron scattering and energy distribution as do transport theory and Monte Carlo procedures, and therefore, can be considered to yield only approximate resuits, especially for deep penetration where straggling becomes important.

However, either one of these techniques, especially Monte Carlo, are generally too time consuming for inclusion as a subprogram in which individual cases are calculated. Monte Carlo or transport calculations could be used to generate individual sets of parametric data for combinations of source energies, and particle sizes giving the dose distribution in tissue, or the approximate source leakage information (i。e, energy and angular distribution) which could serve as input for transport application, or some semiempirical means of calculating the dosage. The precomputed case information could be organized and stored as semipermanent library data to be recalled, properly weighted based on input source spectra, and 
operated upon as required to give dose and/or integral dose.

The generation of Monte Carlo information was briefly discussed with M. J. Berger. (3) Presently he plans to perform Monte Carlo calculations using two programs which are being developed - one to determine leakage spectra from spherical radioactive particles and the other to compute the dosage using the leakage spectra. The first program will be written to accept an arbitrary input leakage spectra.

Data from transport calculations giving beta ray energy dissipation in a variety of single homogeneous media for monoenergetic beta rays have been generated by Spencer (4). Among the various media, are air and polystyrene, but not tissue or water. Any additional calculations would require translation of a program used to calculate the spatial moments from basic machine language to FORTRAN language in order to perform computations on present machines - a task which may take perhaps a month of full time attention. 


\section{INTRODUCTION}

This effort was initiated in response to the need for establishing some reasonably accurate means of determining the beta ray dosage in tissue that would result from contact with a volume-distributed source of radionuclide material. Moreover, it is essential that the calculational scheme be able to accomodate a variety of cases, depending upon specified source characteristics determined by reactor (steady state) operating period (s), shutdown times (s) preferential fission product release, and particle size distribution.

The sections that follow are a description of this effort and the calculational procedure currently recommended for application to ROVER flight safety assessment。

Prior to the completion of this effort, a more detailed Monte Carlo procedure (3) addressed to the beta particle dose problem described herein was initiated. When results of these calculations become available, a more accurate determination of the beta dosage in tissue should be possible. For various input beta source spectra and particle sizes, beta ray energy leakage spectra may be obtained as well as the actual tissue dose. Beta ray leakage spectra, for example, could be used as input information to perform additional calculations, which may be simpler than additional Monte Carlo computations to obtain tissue dosages. The manner in which the Monte Carlo calculations will be used for application to the ROVER flight safety program will depend on the quantity of information required so as to enable suitable interpolation and the comparative accuracy of other methods which may be used jointly.

The experimental work presently in progress at ORNL (2) will provide a basis for comparison of calculational methods with measured results. 


\section{CAICULATIONAL MODELS}

The possibility of a radioactive fuel particle coming into contact with the tissue of an individual in the use of nuclear powered rockets requires that the attendant magnitude of potential hazard be evaluated. Knowledge of the beta dose delivered to the surrounding or adjacent tissue is an index of the hazard, which varies with the beta energy spectra and source particle size as well as with the affected organs. Effective absorbers such as clothing will also make differences in the beta dose to skin. Generally two situations are imagined which regulate the approximate geometry of the calculation model: (1) a beta particle in contact with some portion of the external body skin surface or (2) a beta particle in contact with the soft tissue of some internal portion of the body. Below is a sketch of the model which is considered for purposes of developing a means to calculate the beta ray dose distribution and integral dose (or average dose) for the ease of the fuel particle in contact with the external body.

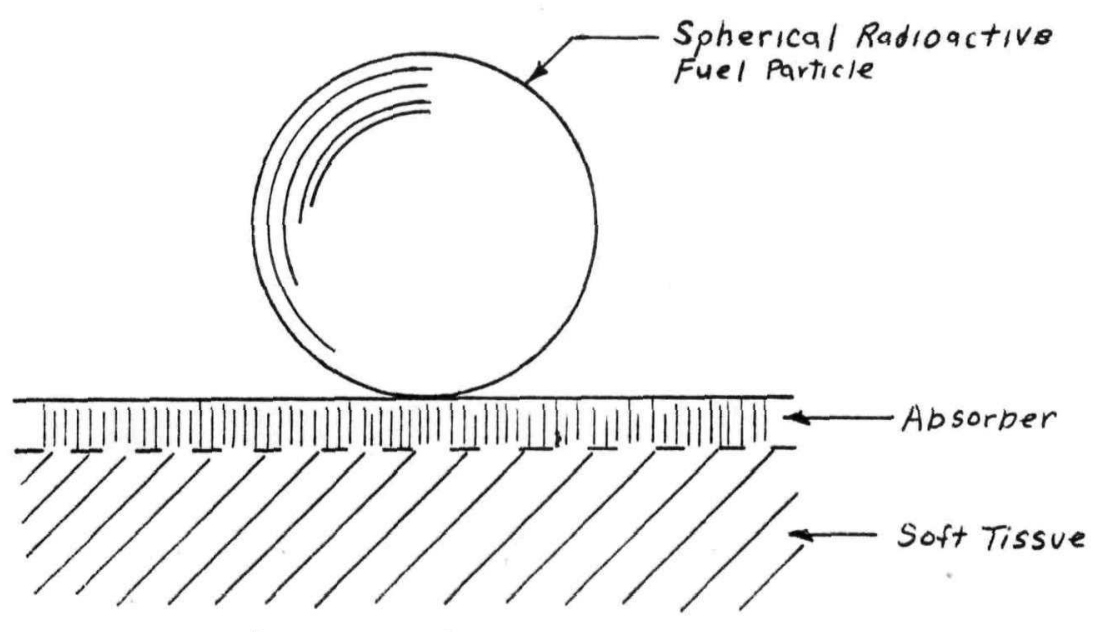


The model for a source particle making contact with internal body tissue is identical except with no absorption between particle and soft tissue. The absorbers are assumed to consist of low $\mathrm{Z}$ material such as clothing and tissue. Most of the external body skin has a natural absorber consisting of about $0.007 \mathrm{~cm}$ of inert tissue. Soft beta rays (less than about $0.1 \mathrm{Mev}$ ) would be effectively stopped by this layer since their maximum practical range is less than $\sim 0.007$ $\mathrm{cm}$. Accordingly, for multi-energy source calculation, emphasis in energy grouping might be placed differently for internal dose calculations than for external dose calculations.

Single energy group calculations in which some effective energy is selected or determined to represent an entire beta ray energy distribution are considered to be less accurate than multi-group calculations for these purposes, since beta ray ranges and penetration abilities vary widely with energy. Therefore, leakage out of source particles would vary considerably depending upon the size. Moreover, the penetration of absorber material such as clothing, etc., would be more accurately described by dealing with the spectrum distribution energies separately.

In spite of preliminary work that has been done commencing as early as 1889 with Rutherford (5), 1929 by Mott (6), and others, and that which is continuing at present utilizing high-speed computer techniques to perform beta transport ${ }^{(4)}$ and Monte Carlo (3) calculations, the fact remains that techniques are still not available for performing expedient beta ray dose calculations similar to those that are used for gamma radiation (e.g., bulldup factors etc.) This 1s particularly true for heterogenous media and monoenergetic source energies -- the conditions of most practical interest here.

Using the sketch shown above as the basic model, calculations were performed to determine a means of computing, first, the leakage dose from a spherical source particle which would not result in excessive machine computations as compared to other dose calculations in the NURSE program (1). Results of the calculations based on exponential, linear, and transport attenuation techniques were compared with experimental data (2); some results are shown below 
Technique

Experimental

Transport

Exponential

Linear
Sulface Contact Dose (averaged over $\mathrm{Rad} / \mathrm{h}$.

$\sim 23$ (est from Figure 1)

146

235

Based on the above results, the exponential model appears to offer simplicity and suitable accuracy for current calculations. The uncertainty, however, lies in coupling the surface dose results, actually, for purposes of including the self absorption affect, to dose determination in the tissue med!a since the spectrum is not explicity dealt with.

The development of these calculations ind athom atical model for present computer applications described the sections which follow. (The program equations are summatized in Appendix.).

A。 EXPONENTIAL MODEL

Exponential dose attenuation of beta rays traveling through matter has been found to be a reasonable approximation for continuous beta ray source spectra (7) (8) (9). The assumption, however, contains the inherent drawback in that straggling toward the end of the beta particle range is not described adequately, owing to the lack of proper specification of the beta spectral changes and angular distribution.

Although a simple calculational method is still lacking for monoenergetic beta source radiation penetration, the assumption here is that over a considerable portion of the beta ray transmission distance in matter, attenuation may be considered to be expcnential. Evans (9) points out that monochromatic beta rays, although or.ginally appear as a single line spectra, exhibit the shape and appearance of a "flattening" distribution with thickness of matter. Furthermore, for continuous spectra, the average energy may decrease, or increase, and then subsequently decrease depending whether $\mathrm{Z}$ is small or large, respectively. However, as Brownell (10) illustrates, the scattering effects of beta radiation are remarkably consistent with the observed changes in angular distribution. 


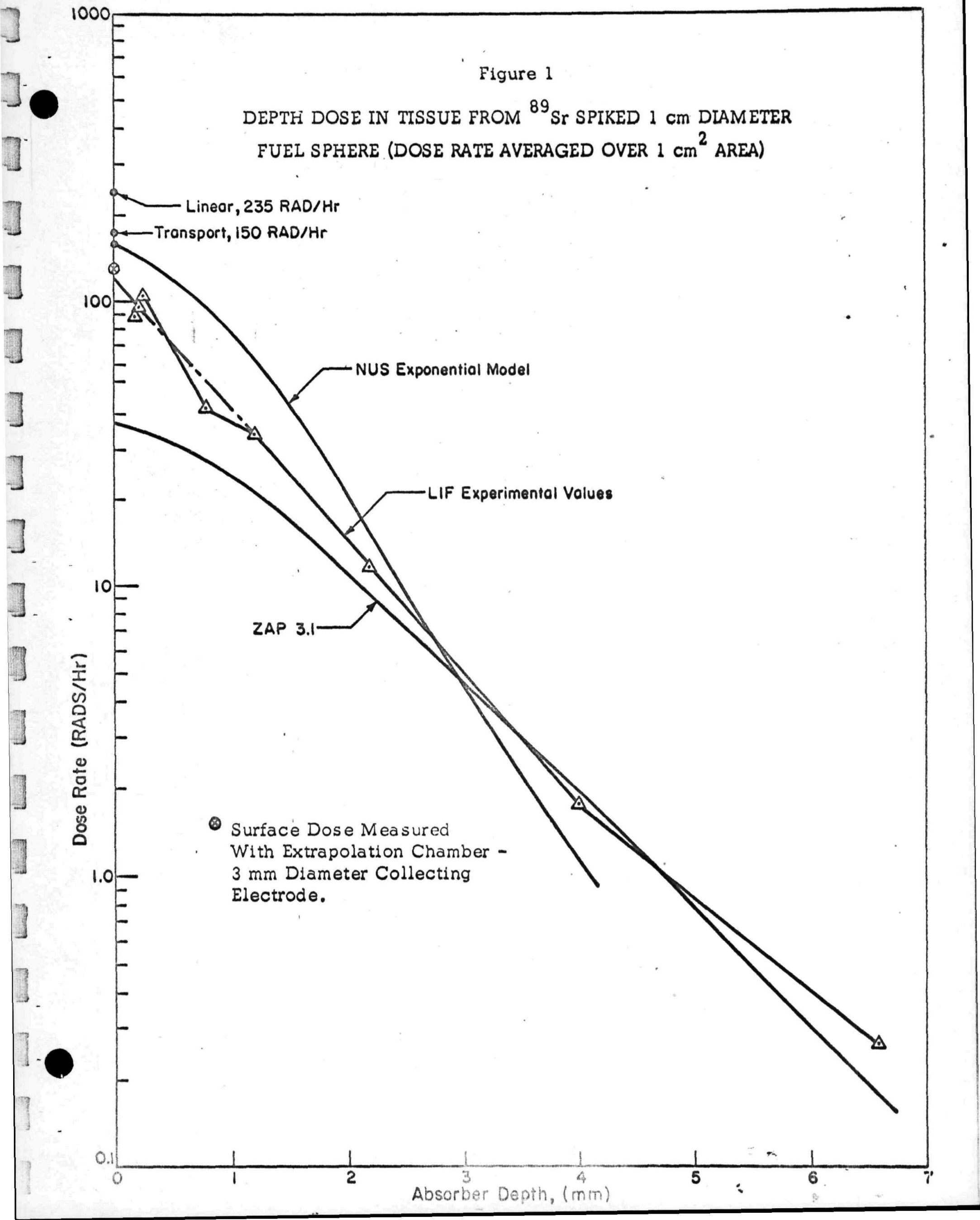


Further, his measurements indicate that, in general, when the rapid changes in the average energy that result from scattering are no longer apparent, the angular distribution has approached an equilibrium form. This, then, strongly suggests that over a considerable range of absorber thickness, the interaction of beta rays with matter can be considered to be a diffusion process in which the average energy of radiation remains relatively constant and the angular distribution of the radiation is random. Brownell further points out that this would appear to be a good approximation for absorber thickness greater than one-half thickness for high-atomic-number absorbers.

It is upon these concepts that the exponential character of beta ray transmission in matter may serve as the basis for development of a model. The problem model for this effort is concerned with: first, determining the "leakage dose" from a spherical radioactive source, and second, determining the beta dose distribution in a media (tissue) adjacent to the particle.

\section{Surface Dose}

The "leakage dose" or dose at the surface of particle is determined by integrating over the sphere (assumed to be homogeneously distributed with radioactive material). It can be shown (Appendix) that for a configuration expressed as follows.

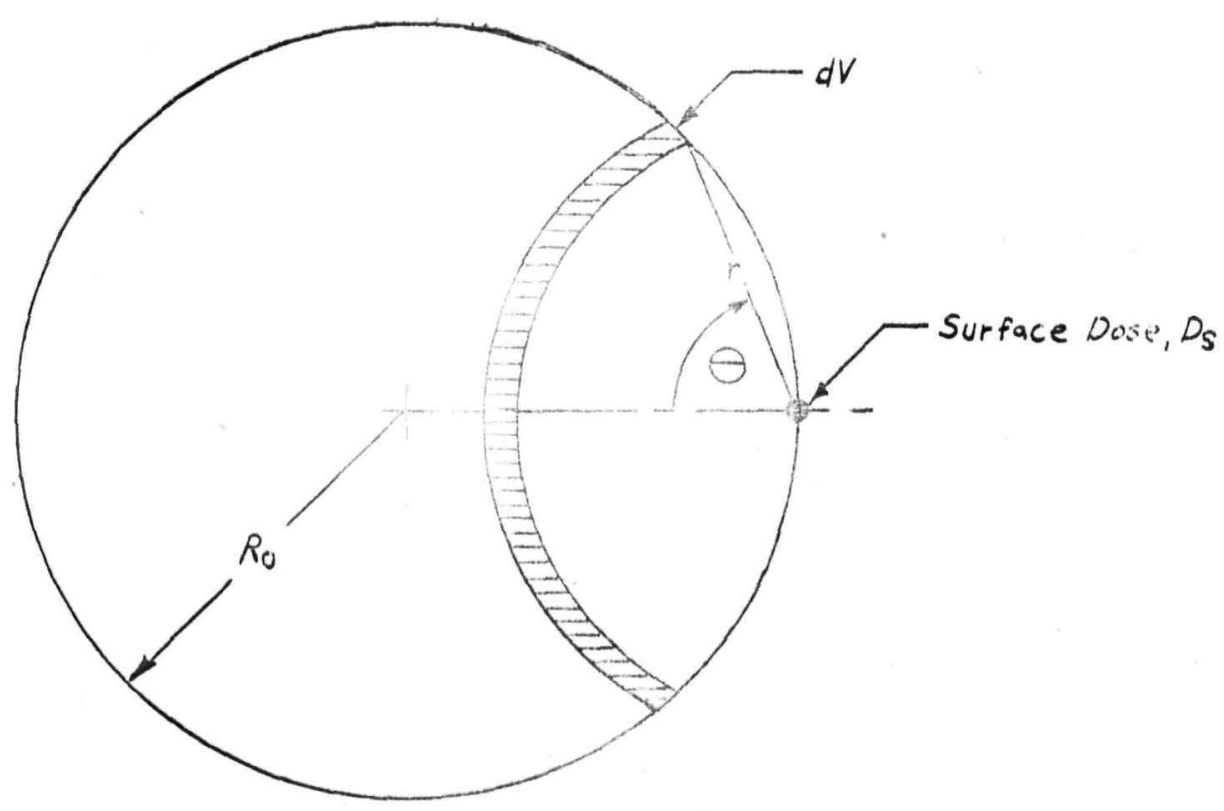


An element of volume may be written as:

$d V(r)=2 \pi r^{2}\left(1-\frac{r}{2 R_{O}}\right) d r$

Using the same exponential form as Rossi (7) for penetration distances less than one beta relaxation length, $1 / \mu_{\mathrm{S}}$, we have

$J_{l}(r)=\frac{K}{r} e^{-\mu_{S} r} \quad r \leq \frac{1}{\mu}$

However, for $r>\frac{1}{\mu_{S}}$, we conform with a form suggested

by diffusion arguments and approximate the dose attenuation as

$J_{2}(r)=\frac{K}{r^{2}} \mu_{S} r e^{-\mu_{S}} \quad r>\frac{1}{\mu_{S}}$

The surface dose, $D_{S}$ is calculated by either a one or two part function depending upon how $2 \mathrm{R}_{0}$ compares with

$\frac{1}{\mu_{s}}, i . e$.

i) if $\frac{1}{\mu_{s}} \geq 2 R_{O}$

$D_{S}=\int_{0}^{2 R} 0 J_{l}(r) d V(r), \quad$ or

ii) if $\frac{1}{\mu_{S}}<2 R_{O^{\prime}}$

$$
D_{S}=\int_{0}^{\frac{1}{\mu_{S}}} J_{1}(r) d V(r)+\int_{\frac{1}{\mu_{S}}}^{2} J_{2}(r) d V(r)
$$


Carrying out the above integrations (Appendix), we have for:

$\frac{1}{\mu_{S}} \geq 2 R_{0}$

$D_{s}=\frac{2 \pi K}{\mu_{s}} \quad\left(1-\frac{1}{2 \mu_{s} R_{0}}+\frac{e^{-2 \mu_{s} R_{0}}}{2 \mu_{s} R_{0}}\right)$

and for

$\frac{1}{\mu_{S}}<2 R_{0}$

$D_{S}=\frac{2 \pi K}{\mu_{S}}$

$$
\left[\frac{e\left(2 \mu_{s} R_{0}-1\right)+2 \mu_{s} R_{0}-3}{2 e \mu_{s} R_{0}}+\left(1+\frac{1}{\mu_{s} R_{0}}\right) e^{-2 \mu_{s} R_{0}}\right]
$$

If $D_{S}$ is expressed in units of $\mathrm{rad} / \mathrm{hr}, \mathrm{K}$ is given by:

$K=\frac{S(E) E E(E) \alpha(E)\left(3.6 \times 10^{3}\right)\left(1.602 \times 10^{-6}\right)}{4 \pi V\left(10^{2}\right)} \quad\left(\frac{\mathrm{rad}}{\mathrm{hr}-\mathrm{cm}}\right)$

The upper limit of integration is not taken as the maximum betá particle ránge, $R_{m}$ as no uid, strictly speaking be appropriate for $R_{m}<2 R_{0}$. Integrating to an upper limit of $2 \mathrm{R}_{0}$, would introduce on insignificant amount of overestimate error.

This calculational procedure is developed for a beta source energy distribution such as would be generated from a fission process。

Such energies of a gross decaying assembiy of fission products may range from hundreths of a $\mathrm{Mev}$ to an effective maximum of around $8 \mathrm{Mev}$. The spectra shape are, of course, dependent upon both the duration of fission, temporal variation of fission rate, and time after fission period. This calculational procedure approximates beta ray dose behavior for betas in a discrete interval of, $\Delta E=E_{i}-E_{i-1}$, as illustrated in the sketch below 


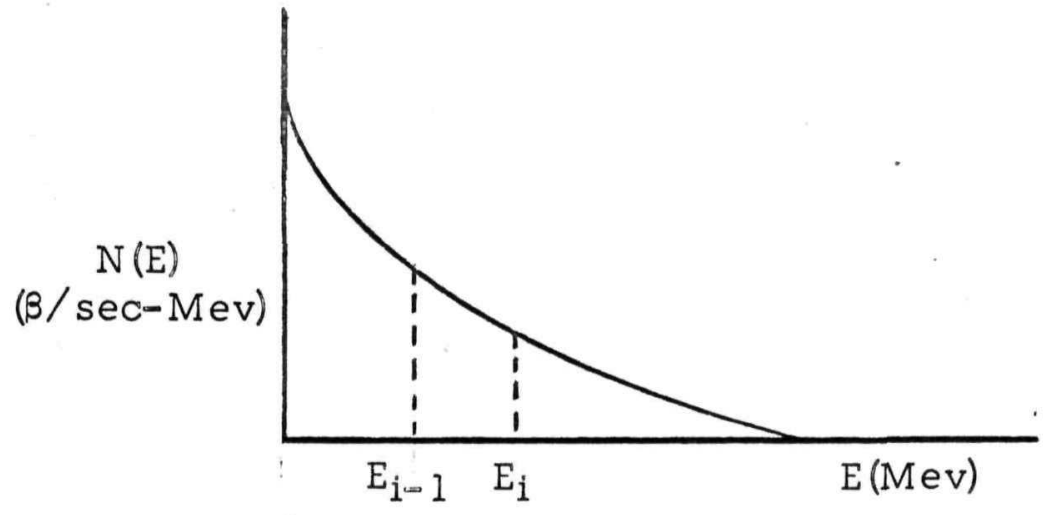

in which dose calculations are performed for each one of the intervals; and the total dose is then obtained by summing over energies of the spectra. This is equivalent to commencing with a collection of single line spectra and applying exponential dose attenuation to each of these source line energies. With this, the calculations assume that the average energy $\bar{E}_{i}$ are specified as input information obtained from an arbitrary beta ray spectra, $N(E)$ betas/sec-Mev。 $\bar{E}_{i}$ and $S_{i}(E)$ are assumed to be consistent with the following definitions:

$$
\bar{E}_{i}=\frac{\int_{\Delta E} E N E d E}{\int_{\Delta E} N(E) d E}
$$

and

$$
S_{i}(E)=\int_{\Delta E} N \cdot E d E
$$


It should be pointed out here that exponential attenuation has been associated with source spectra for particular branching ratios of radionuclides, which would generally be different in shape than would be expected from a whole collection of such nuclides in a gross decaying assembly. This, incidently suggests an alternate approach in that the possibility of treating each nuciide branching ratio as a separate calculation exists, since for exponential attenuation, only a single set of "effective parameters" may be utilized for the whole branching ratio distribution. This approach, although attractive, was not pursued for the time being, owing to the anticipated large number of calculations which might be necessary. Also, it is not clear that such an approach would add significantly to the calculational accuracy owing to the heterogeneity of the media of concern here; i.e. a high effective $Z$ particle $(\bar{Z} \simeq 84)$ and a low $Z(\sim 7)$ absorber with the simplified geometric model assumed here.

Evans (9) points out the fact that the apparent beta ray absorption coefficient for a beta ray energy source distribution is characteristic of the maximum energy and, moreover, remains essentially constant with material absorber thickness. This concept is also borne out by Loevinger $B$ in his work with sources in light $Z$ material. The essential point to be gained from these adications and then to be applied to the expon atculation here is simply that $t \ldots \ldots . . . x+m$ energy, $E_{1}$, of the interval $\Delta E$ ought to sea detemining the dose from betas; accoranly ar sorption coefficient in tissue 3 cbtched utilizing Loevinger's relistion 3 . $V(E)=\frac{18.6}{\left(E_{i}-0.036\right) 1.37}\left(\mathrm{~cm}^{2} / \mathrm{gm}\right)$ 
The value of $\propto(E)$ which is determined, based on the upper limit of a beta ray energy interval, is a value which is part of the Loevinger dose conversion constant, semi empirically derived based on conservation of source energy. Actually, the type of functions used in this calculational procedure to determine the particle leakage dose are different from those used by Loevinger for making tissue dose calculations insofar as attenuation of radiation in the particle is concerned. However, since the dose in tissue is of concern at the particle surface, and furthermore, as will follow later, the dose distribution in tissue outside the particle is of interest, for which Loevinger's attenuation relationships are directly used, the value of $\alpha(E)$ is used in the dose conversion constant, K. Accordingly, $x(E)$ is given as (8).

$x(E)=\left[3 C^{2}-(C-1) e\right]^{-1}$

where:

$C=3.11 e^{-0.55 E_{i}}$

In the constant, $\mathrm{K}$, above, $\mathrm{V}$ is the volume of the spherical source particle.

Monoenergêtic beta ray mass absorption coefficients, especially for composite high $Z$ materials, such as a ROVER fuel particle, are nonexistent; it is therefore necessary to select some material such as aluminum for which data is readily available. Adjusting for the physical density and making some adjustment for a differen $Z$ it seems should yield reasonable results for se calculations in view of the lack of data. Such data however, are presently being generate, expermentally at ORNL ${ }^{(2)}$. With this, the linear sorption coefficient based on aluminum ${ }^{(9)}$, may be given by 


$$
\mu_{S}(E)=\frac{17 \rho_{S}}{E_{i}^{1.14}} \quad f(E) \mathrm{cm}^{-1}
$$

The particle density is $\rho_{S}$, and $f(E)$ is a ratio of the stopping powers of an equivalent $\mathrm{Z}$ material for the particle to that of aluminum. Since a cross-section may be written in terms of the total stopping power, $\frac{-d E}{d X}$, which includes both radiative and collision energy losses; i。e.

$$
\sigma \equiv \frac{1}{N Z E}\left[\frac{d E}{d X}\right] \mathrm{cm}^{2} / \mathrm{e} .
$$

The mass absorption coefficient, $\mu / \rho$, is given as

$$
\frac{\mu}{\rho} \approx \frac{N Z_{\sigma}}{\rho}=\frac{1}{E}[
$$

The ratio of mass absorption coefficients. $f(E)$, is then given by the ratio of total stopping powers. With an average atomic number of 84 for the fuel particle, lead $(Z=82)$ is taken as a reference or effective $Z$ material to determine:

$$
f(E)=\frac{\left(-\frac{d E}{d X}\right)_{P b}}{\left(-\frac{d E}{d X}\right)_{A l}}
$$

Using the recent data of Berger and Seltzer(11) plotted in Figures 2 and 3 , nine functional relationships were obtained for $f(E)$ covering the range from 0,01 to 8. $0 \mathrm{Mev}$. Any paritcular function can be designated by a machine program energy scan procedure. These functions are given in the equation summary section containing the equations for machine programming . 


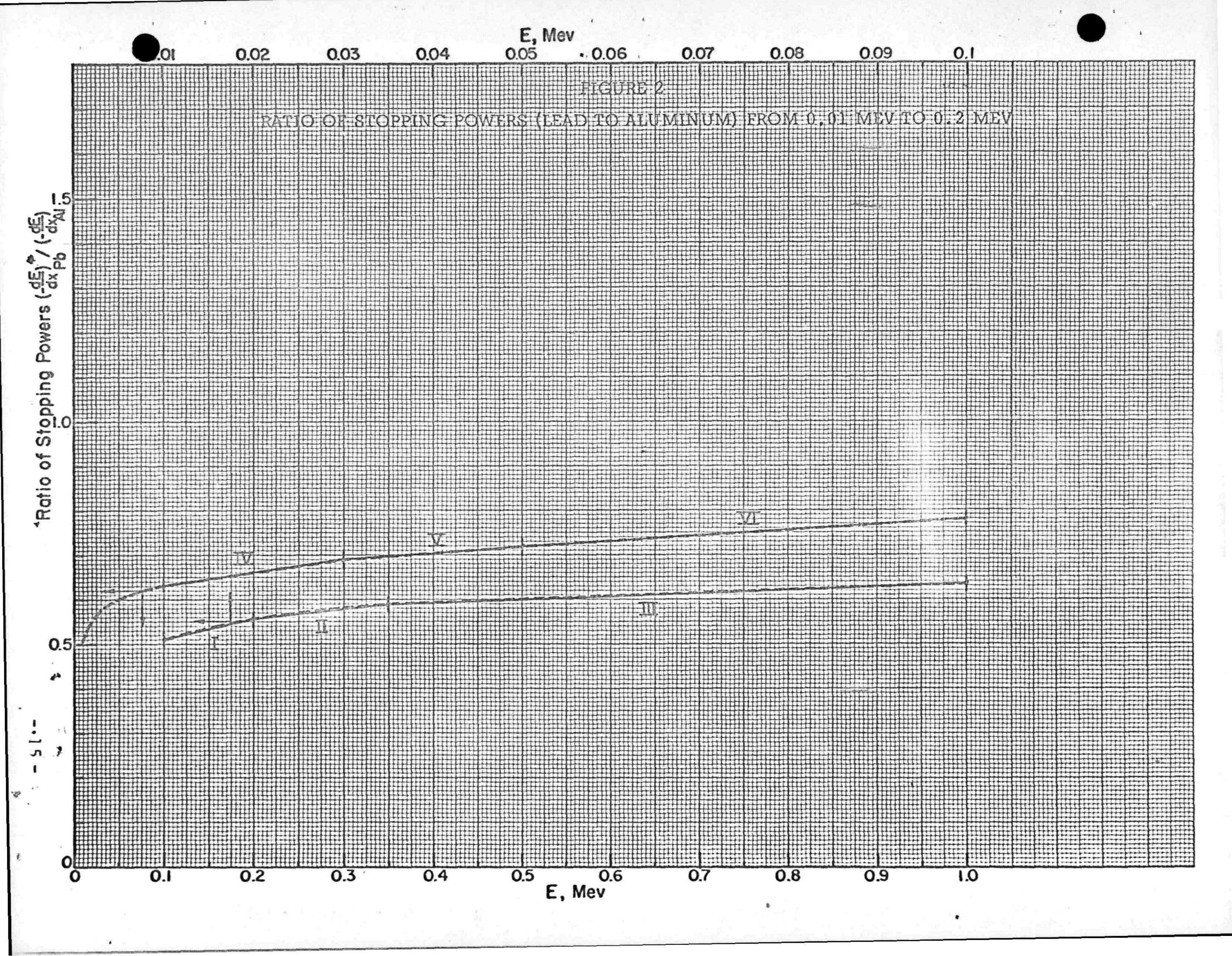


Using the above techniques, surface or leakage dose calculations were performed in order to make comparisons with experimental data developed at ORNL ${ }^{(2)}$. At ORNL, dose beta measurements were made with a $1.0 \mathrm{~cm}$ diameter spherical $\mathrm{UO}_{2}-\mathrm{C}$ source spiked with $\mathrm{S}_{r}-89$. Based on information supplied by ORNL, the following data were used in making: the calculations:

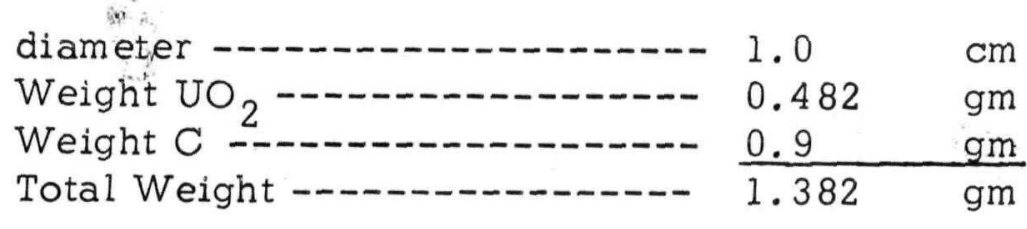

$$
\begin{aligned}
& \text { Volume }=\frac{4}{3} \pi\left(\frac{1}{2}\right)^{3} \quad 0.523 \quad \mathrm{~cm}^{3} \\
& \text { Density }=\frac{1.382}{0.523} \quad 2.64 \quad \mathrm{gm} / \mathrm{cm}^{3} \\
& \bar{z}=\frac{1}{1.382}\left[\frac{235}{267}(0.482)(92)+\frac{32}{267}(0.482)(8)+\right. \\
& 0.9(6)]=32.5
\end{aligned}
$$

The beta ray source spectra data plotted in Figure 4 obtained from the NRDL tape (12) was used in the calculations. This spectra was more or less arbitrarily divided up into six discrete energy source groups with the source strengths, $S(E)$, for the $1.4 \mathrm{mc} \mathrm{S}_{\mathrm{r}}-89$ source given as

Beta ray energy, Mev

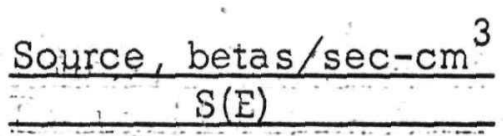

$\begin{array}{lll}\frac{\bar{E}}{0.05} & & \frac{E}{2.1} \\ 0.2 & & 0.3 \\ 0.4 & & 0.6 \\ 0.7 & & 0.9 \\ 1.0 & & 1.1 \\ 1.25 & & 1.5\end{array}$

$3.72 \times 10^{6}$
$8.99 \times 10^{6}$
$1.49 \times 10^{7}$
$1.36 \times 10^{7}$
$6.72 \times 10^{6}$
$3.95 \times 10^{6}$


(4) 1.0

]

7

$-0.8$

]

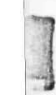

0.7

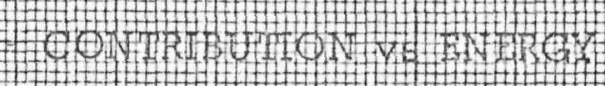

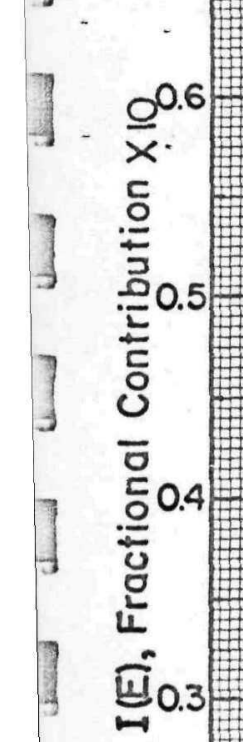
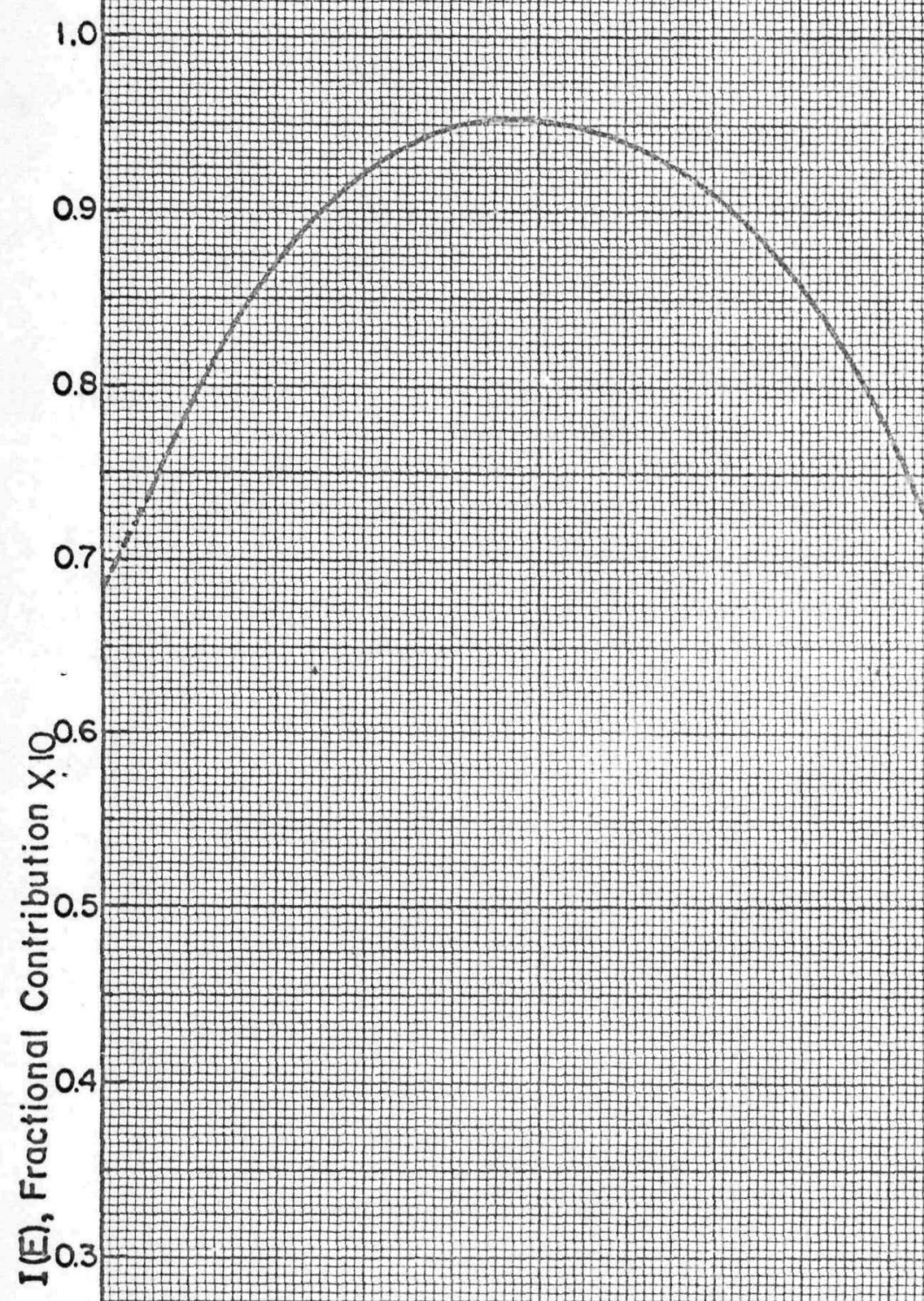

0.2
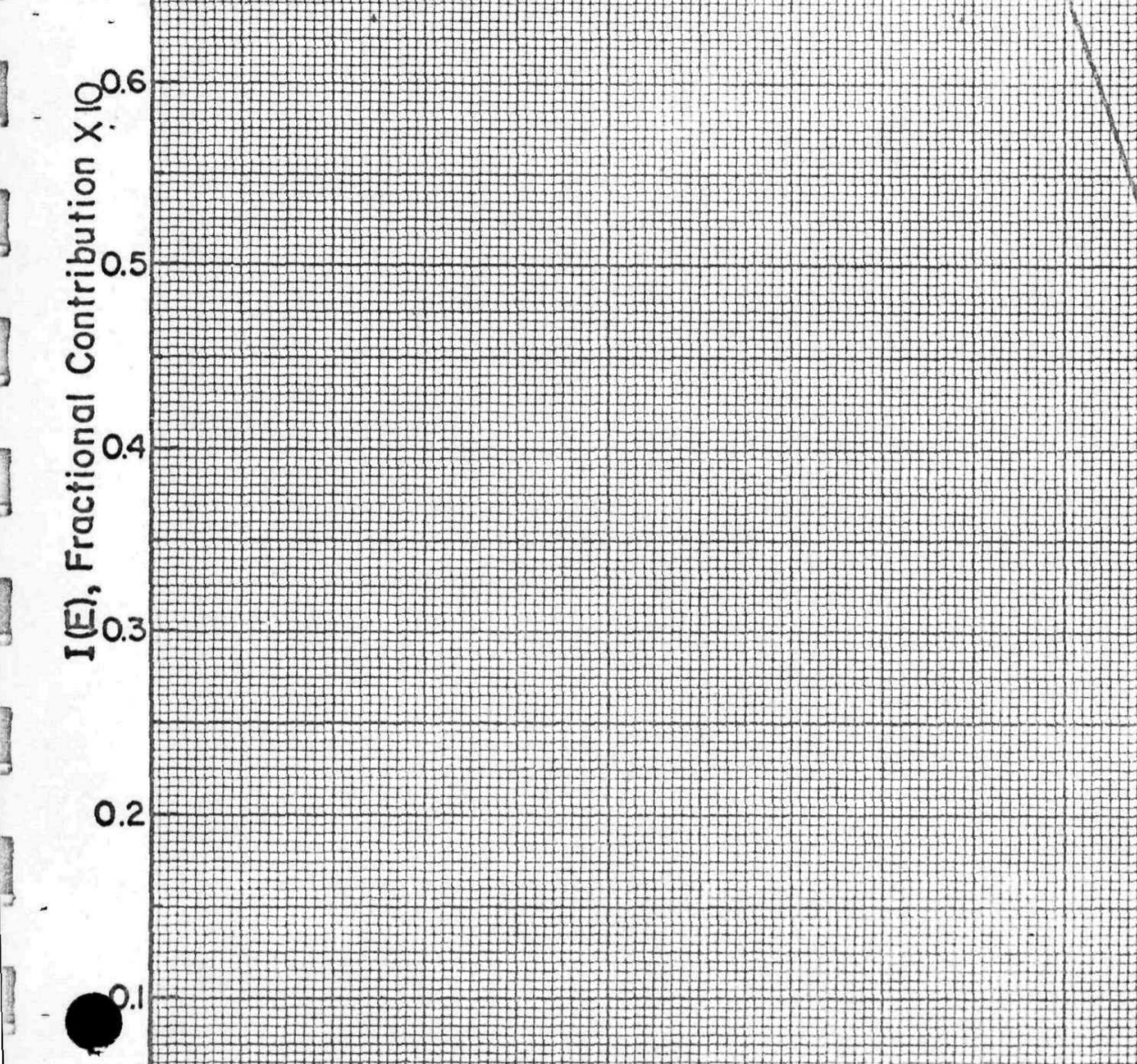

0
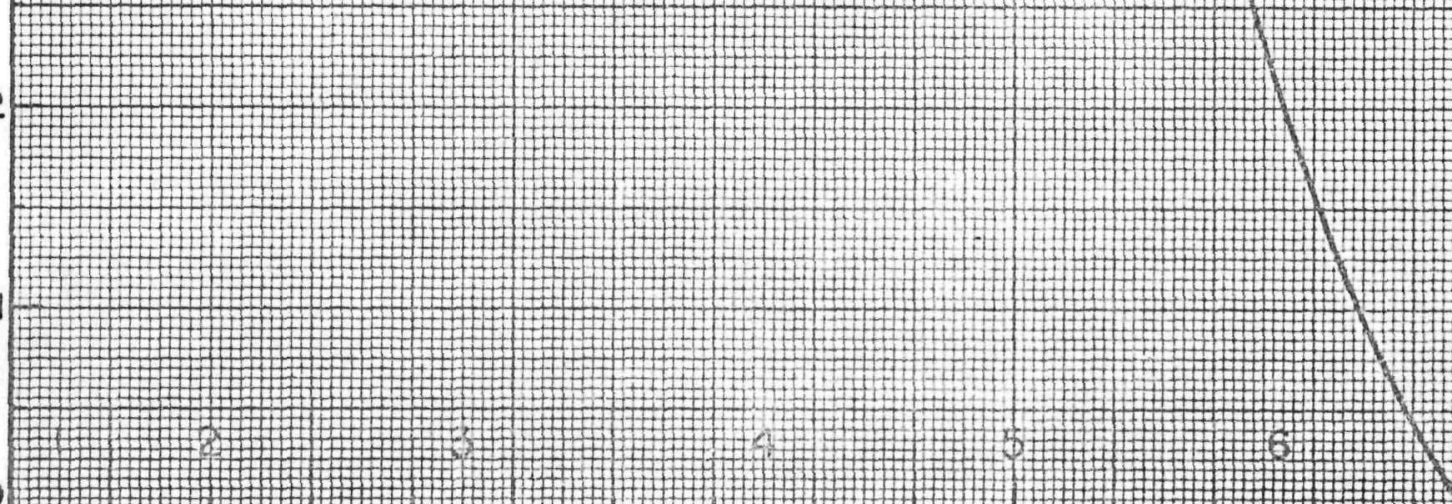
The average energy, $\overline{\mathrm{E}}$, given above was not strictly speaking, obtained according to the definition above, but rather is simply an "eye ball" approximation to this quantity. Also, since the stopping power of aluminum is not significantly different that that of copper, the equivalent $\mathrm{Z}$ material for the $\mathrm{UO}_{2}-\mathrm{C}$ particle, no correction or adjustment for $Z$ was made. Neglecting this correction will tend to somewhat elevate the surface leakage dose; however, it is assumed to be relatively small for purposes of this particular calculation.

The calculated surface dose, $\mathrm{D}_{\mathrm{s}}$, is $276 \mathrm{Rad} / \mathrm{hr}$. In order to compare this with the ORNL data, average surface dose is determined.

The ORNL dose rate values are averaged over 1.0 $\mathrm{cm}^{2}$. The $1.0 \mathrm{~cm}^{2}$ is assumed to be a circular surface upon which the spherical particle is resting; i.e., viz:

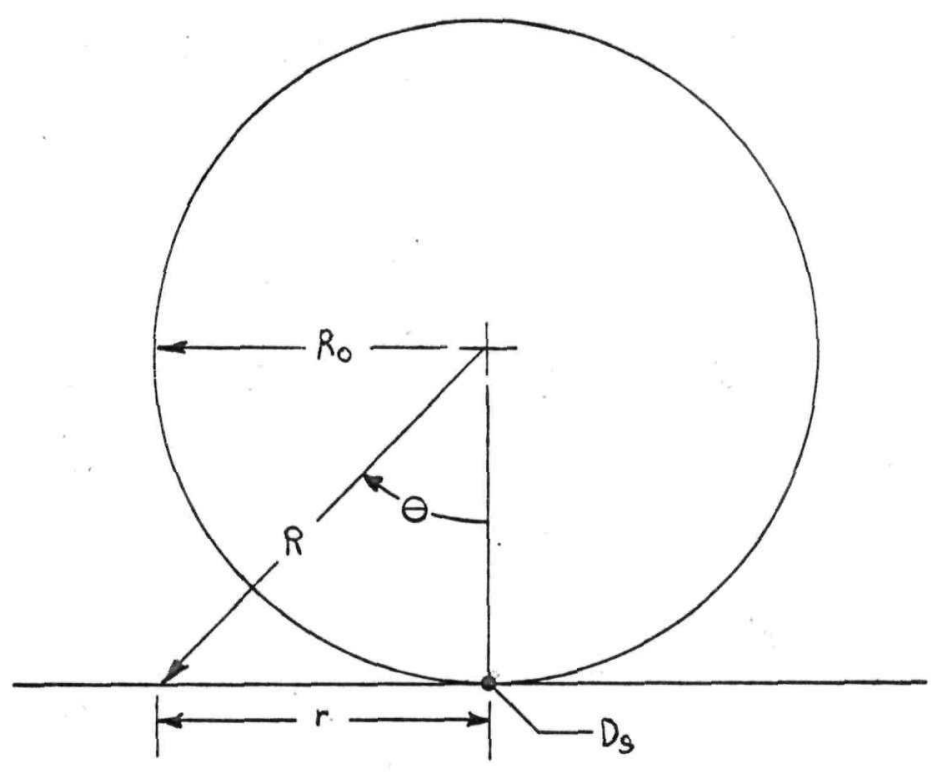


Assuming a $\frac{1}{2}$ variation, the average surface dose $d \bar{D}_{s}\left(\frac{R_{e}^{2}}{R_{0}^{2}+r^{2}}\right) \cos 2 \pi r d r$

and

$D_{S}=2 \pi D_{S} R_{O}^{3} \int_{0}^{\frac{1}{\sqrt{\pi}}} \frac{r d r}{\left(R_{0}^{2}+r^{2}\right) 3 / 2}$

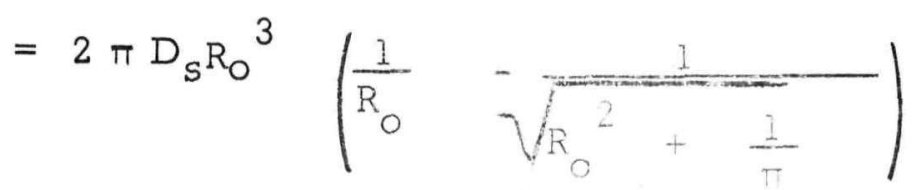

Using the calculated value of $D=275 \mathrm{Rad} / \mathrm{hr}$ for a spherical particle of $05 \mathrm{~cm}$.h. $146 \mathrm{Rad} / \mathrm{hr}$ for the average surface cose. This value agrees fairly well (Figure 1) with experimental ORNL data.

\section{Dose Distribution}

Beta ray dose distribution in tissue media has received considerable attention due mainly to uses stemming from clincal applicafion and neoplasm therapy. Loevinger and others (8) have developed semiempirical calculational ray techniques for determining the dose distribution in tissue for various beta ray sources. The dose distribution calculation model for these computations utilizes this technique directly for the tissue portion. The main disadvantage of this technique is the fact that the be leakage energy spectrum is not specified to permit attenuation parameters to be selected accurately. Accordingly, they are selected based on the original source energy - this is supported somewhat by relative constancy of the beta absorption coefficient (mentioned above in section III-A-1).

The dose distribution is calculated based on the following model (Figure 5) by specifying the vector distance, $\bar{R}$, from the center of the spherical particle to the point of interest. The direction of $\bar{R}$ is based on the orientation at an angle, from the normal to the surface. 

The model has symmetry in the azimuthal angle, $\Phi$, consisting of a spherical source which may or may not have a coating, adjacent to a semi-infinite half space made up of an absorber to simulate clothing and an inert tissue layer. The model in Figure 5 indicates a particle coating thickness, $t_{C}$, which may be a relatively light $Z$ material of $\sim 10$ microns. This calculational model, however, assumes $t_{C}=0$ 。 The equations for the case in which it is assumed that $t_{C} \neq 0$ are given in the Appendix. The absorber is optional and may be designated as having zero thickness in order o mulate ar ternal beta dose situation. For sim $1 / \mathrm{K}^{2}$ elationship is assumed for the geometrical variation in the dose attenuation: this ass pption would no be the source of appreciable error lew of the other uncertainties associated with this calculational technique. This can be shown by considering the geometrical variation of radiation intensity with distance from a spherical surface source giving off particles which are assumed to be emitted from the source surface with a cosine distribution measured from the surface normal; the following sketch illustrates this.

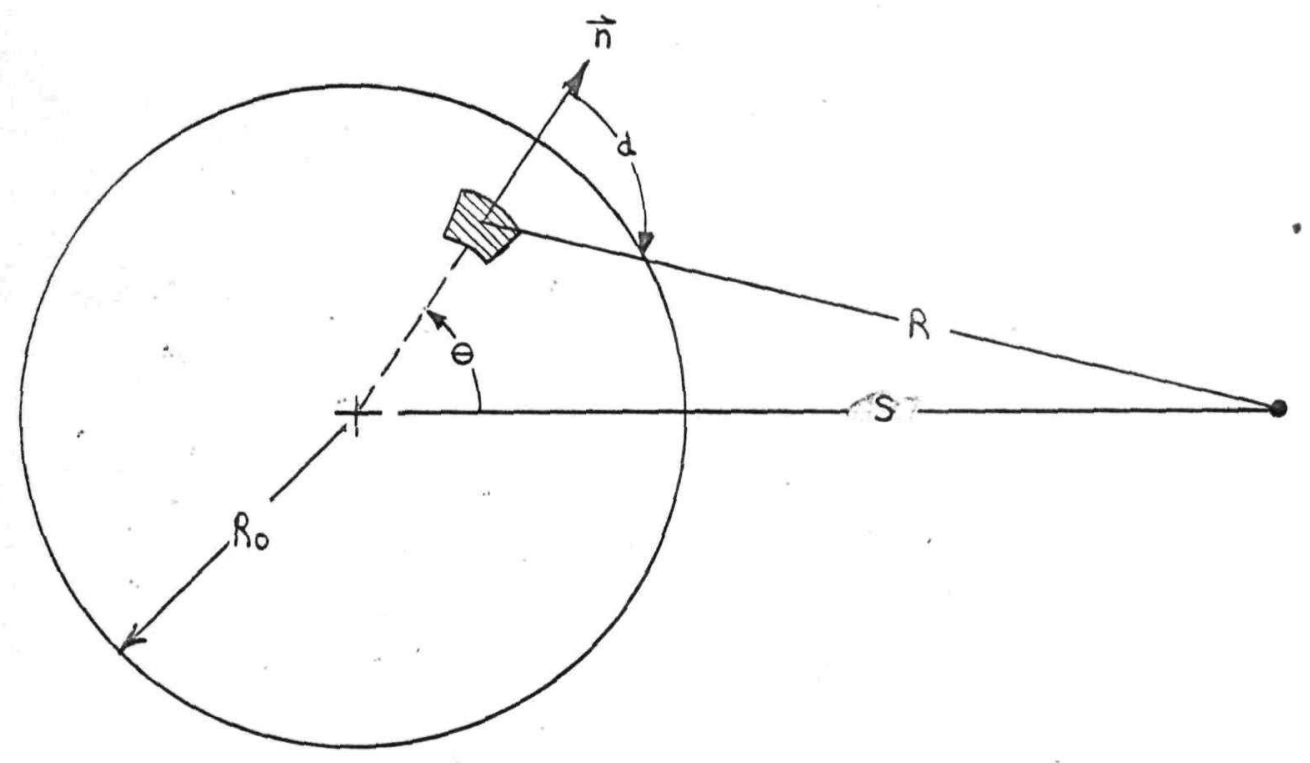


As shown in the Appendix, the intensity at a distance $S$, from center of the source sphere of radius, $R_{O}$, may be given as

$$
\begin{aligned}
& I=\frac{S_{a}}{2}\left[1-\sqrt{1-\left(\frac{R_{0}}{S}\right)^{2}}\right] \\
& \text { Expanding } \sqrt{1-\left(\frac{R_{0}}{S}\right)^{2}} \text {, we have: } \\
& I=\frac{1}{2}\left\{I-\left[1-\frac{1}{2}\left(\frac{R_{0}}{S}\right)^{2}+\frac{(I / 2-1)}{2 \cdot 2 !}\left(\frac{R_{0}}{S}\right)^{4}\right.\right. \\
& \left.\left.-\frac{(1 / 2-1)(1 / 2-2)}{2 \cdot 3 !}\left(\frac{R_{0}}{S}\right)^{6}+\ldots\right]\right\} \\
& \simeq \frac{S_{a}}{4} \cdot\left(\frac{R_{0}}{S}\right)^{2} \text { for } R_{0}<<S
\end{aligned}
$$

Evaluating the first three terms of the series illustrates the approximate relative underestimate which is accepted by 
assuming the $1 / \mathrm{R}^{2}$ geometrical variation; rewriting we have:

$$
I=\frac{S_{a}}{4}\left(\frac{R_{0}}{S}\right)^{2}\left\{1+1 / 4\left(\frac{R_{0}}{S}\right)^{2}-\frac{3}{48}\left(\frac{R_{0}}{S}\right)^{3}-\ldots\right\}
$$

The value of the curly bracket is evaluated in term s of $\frac{R_{0}}{S}$ as given below:

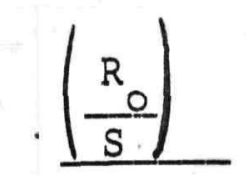

1

0.8

0.75

0.5

0.1

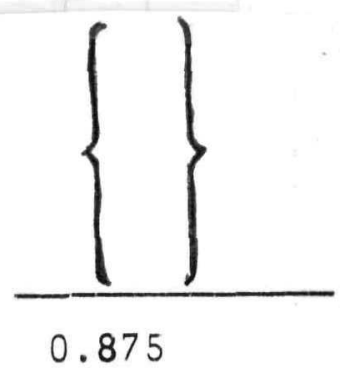

0.8913

0.9175

0.9543

0.9975

Assuming the $l / R^{2}$ variation, the dose distribution as a function of $R$ and $\theta$ is written as follows

i) for $X(R, \theta) \leq C$

$$
\begin{aligned}
J(R, \theta)= & \frac{D_{S} R_{O}^{2}}{R^{2}}[C, \theta \\
& \left.+X(R, \theta) e^{1-X(R, \theta)}\right]
\end{aligned}
$$


ii) for $X(R, \theta)>C$

$$
J(R, \theta)=\frac{D_{S} R_{O}^{2}}{R^{2}}\left[X(R, \theta) e^{1-X(R, \theta)}\right]
$$

where

$$
\begin{gathered}
X(R, \theta)=\mu_{R}+T_{N} \sec \theta \\
T_{N}=\left[\sum_{n=1}^{N} \mu_{n} t_{n}-\mu\left(R_{0}+\sum_{n=1}^{N} t_{n}\right)\right]
\end{gathered}
$$

$\mu$ and $H_{n}$ are linear beta ray absorption coefficients for respectively, tissue and the $n^{\text {th }}$ absorber thickness, $\mathrm{cm}^{-1}, t_{n}$, is the thickness of the $n^{\text {th }}$ absorber material; the absorption coefficient of tissue or tissue-like material, so far as $Z$ is converned, may be determined from

$$
\mu_{n}=\frac{18.60_{n}}{(E-0.036)^{1.37}} \mathrm{~cm}^{-1}
$$

where $o_{n}$ is the physical density, $\mathrm{gm} / \mathrm{cm}^{3}$. 


\section{Integral and Average Dose}

The integral and average doses are ohtained by integrating $J(R, \theta)$ over à specified spherical shell volume. According to the sketch given above. (Figure 5) of the calculational model, integrated doses are calculated (in terms of gm-rad tissue) in a region which is bounded by surfaces which are specified by input information for the spherical coordinate system. These surfaces are given by the locus of a vector $\overline{\mathrm{R}}_{\mathrm{k}}$ and a flat plane, either $R(\theta)$ for the case when absorbers are present, or $R_{\mathrm{O}} \operatorname{Sec} \theta$, when no absorbers are present. Calculating the dose for a region bounded by $\bar{R}_{k}$ for which $k^{\prime} \neq k$, and 'subtracting, (i。e。for $R_{k^{\prime}}>R_{k}$ ) gives the integrated dose within a specified shell for this model.

$$
D_{k^{\prime}, k}=D_{k^{\prime}}-D_{k}
$$

The average dose is then given by

$$
\bar{D}_{k^{\prime} k}=\frac{D_{k^{\prime}, k}}{V_{k^{\prime}}-V_{k}}
$$

where,

$$
\begin{aligned}
& v_{k}=\frac{2 \pi}{3}\left[S_{N}^{3} \operatorname{Tan}^{2} \theta_{k}+R_{k}^{3}\left(\operatorname{Cos} \theta_{k}-1\right)\right] \mathrm{cm}^{3 *}, \\
& \theta_{k}=\operatorname{Cos}^{-1}\left(\frac{S_{N}}{R_{k}}\right) \\
& S_{N}=\left[R_{0}+\sum_{n=1}^{N} t_{n}\right] \\
& R_{k}=\text { radius limit, input specification, } \mathrm{cm} .
\end{aligned}
$$

* See Appendix 
There are three basic cases involved in the dose integration which cover the calculational model functional discontinuties and region boundaries, since $J_{l}$ exists only in the region bounded by $R_{0} \operatorname{Sec} \theta$ and $l(\theta)$ for all $\Phi$, and $J_{2}$ exists only in the region whose lower radial boundary is $I(\theta)$ for all $\bar{\Phi}$. Together with $I_{1}$ and $I_{2}$ as described above, the three cases are determined by the specified arbitrary value of $R_{\mathrm{k}}$. Accordingly, we have;

$$
\begin{aligned}
& \text { when } R_{k} \leq R_{I} \text {, } \\
& \qquad D_{k}=\int_{0}^{\theta_{k}} \int_{R(\theta)}^{R_{k}} d J_{l}
\end{aligned}
$$

or when $R_{\mathrm{I}}<R_{\mathrm{k}} \leq R_{\mathrm{II}}$ 。

$$
\begin{aligned}
D_{k}=\int_{0}^{\theta_{k x}} \int_{R(\theta)}^{l(\theta)} d J_{l} & +\int_{\theta_{k x}}^{\theta_{k}} \int_{R(\theta)}^{R_{k}} d J_{l} \\
& +\int_{0}^{\theta_{k x}} \int_{l(\theta)}^{R_{k}} \mathrm{dJ}_{2} 。
\end{aligned}
$$


or when $R_{k}>R_{I I}$

$$
D_{k}=\int_{0}^{\theta} \int_{R(\theta)}^{I(\theta)} d J_{I}+\int_{0}^{\theta} \int_{I(\theta)}^{R_{I I}} d J_{2}+\int_{0}^{\theta_{I I}} \int_{R_{I I}}^{R_{k}} d J_{2}
$$

$$
+\int_{\theta_{I I}}^{\theta_{k}} \int_{R(\theta)}^{R_{k}} d J_{2}
$$

The zone and region limits for the above integrals are developed in the Appendix, and are given below according to the calculational model illustrated in the sketch of Figure 5。 Some of these are energy dependent, but here they are not subscripted as such; the program equations given in the Appendix are, however, indexed appropriately.

$$
\begin{aligned}
& R_{I}=\frac{C-T_{N}}{\mu} \\
& \theta_{I}=\cos ^{-1}\left[\frac{S_{N}}{R_{I}}\right] \\
& l(\theta)=R_{I}+R_{O}(\sec \theta-1) \\
& R(\theta)=s_{N} \sec \theta \\
& \theta_{k x}=\sec ^{-1}\left[\frac{R_{k}+R_{0}-R_{I}}{R_{0}}\right]
\end{aligned}
$$




$$
\begin{aligned}
& \theta_{I I}=\operatorname{Sec}^{-1}\left(\frac{R_{I}-R_{O}}{S_{N}-R_{O}}\right) \\
& R_{I I}=\left(\frac{S_{N}\left(R_{I}-R_{O}\right)}{S_{N}-R_{0}}\right) \\
& \text { When } \sum_{n=1}^{n} t_{n}=0, \text { (i.e., no absorbers are speci- }
\end{aligned}
$$

fied) $\theta_{\text {II }}$ and $R_{\text {II }}$ tend toward infinity, and are therefore non-existent for these calculations. Disregarding them for this case will be done under program interrogation and control.

In order to simplify the calculations somewhat, an approximate form of $J_{1}(R, \theta)$ other than as given above, was determined by assuming a linear relationship for $J_{I}[X(R, \theta)]=J(x)$ for $0 \leq \mathrm{x}<\mathrm{C} / \mathrm{\mu}$. Figure 6 above gives $\mathrm{J}(\mathrm{x})$ plotted both in terms of the linear approximation and the actual function for some different values of $\mathrm{C}=1,1.5,2$ and 3 . The linear approximation ( solid. line of Figure 6 is given by

$J_{1}(R, \theta)=\frac{D_{S} R_{0}^{2}}{R^{2}} \quad\left[X(R, \theta)\left(e^{1-C}-1\right)+C\right]$ Representation of $J_{I}(R, \theta)$ in this form does not jeopardize accuracy to excess. A numerical indication of this may be gleaned by evaluating $\frac{\int_{0}^{\frac{\mu}{C}} J(x)_{\text {linear }} d x}{\int_{0}^{\frac{\mu}{C}} J(x) d x}=\frac{F^{\prime}}{F}$ 


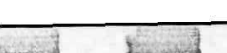

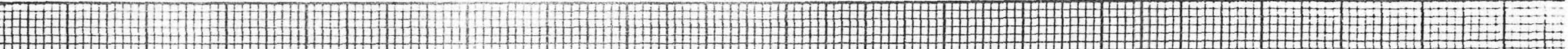
(๐) \begin{tabular}{l} 
(n) \\
\hline
\end{tabular} (\#) \#

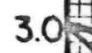

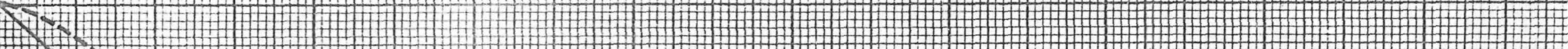
(ํ)

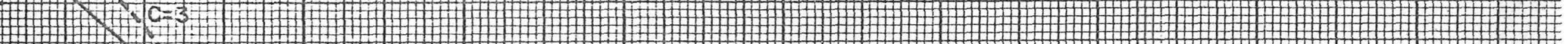

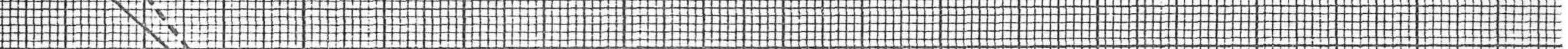
(ํ)

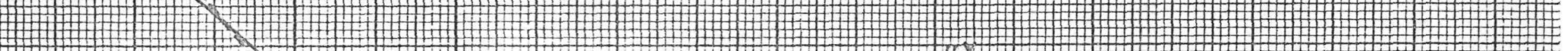

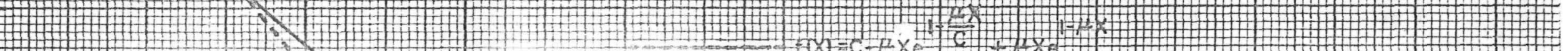

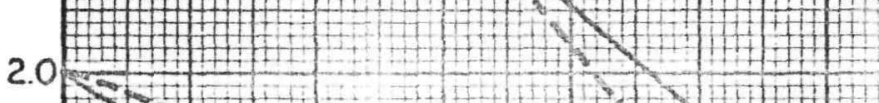

i $1+1$

${ }_{i}^{\omega}$

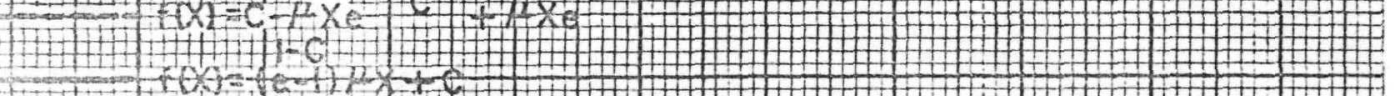
TIt Tit (1) 난 14 1

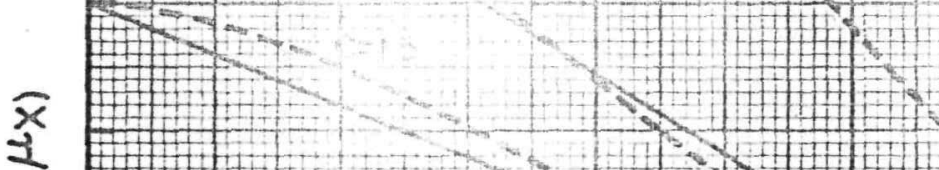
ç

$\frac{1}{4}$

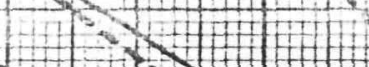
(1)

$1.0 \div$

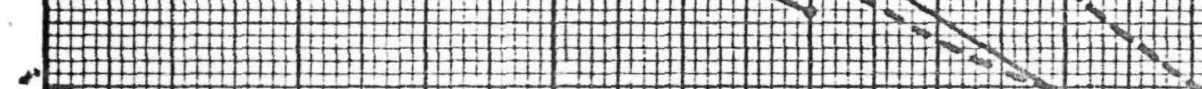

I

[

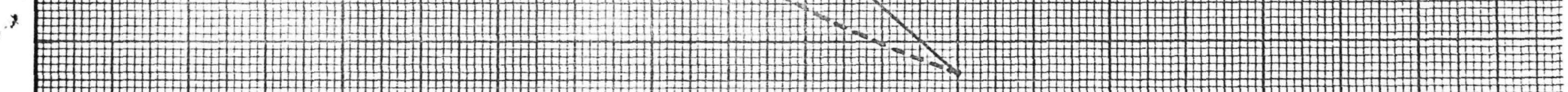
Æ.

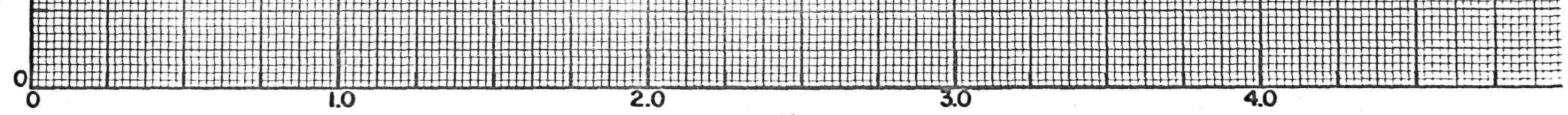
$\mu \times$ 3.0

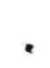


where for:

$$
J(x)_{\text {linear }}=\left(e^{1-C}-1\right) \mu_{x}+C
$$

and

$$
\begin{aligned}
& J(x)=C-\mu_{x} e^{1-\mu x / C}+\mu_{x} e^{1-\mu x} \\
& F^{\prime}=\frac{C^{2}}{2^{\mu}}\left[(C+1) e^{-C}-1\right]
\end{aligned}
$$

and

$$
\begin{aligned}
& F=\frac{1}{\mu}\left\{C^{2}+C^{2} e\left(2 e^{-1}-1\right)-e\left[(C+1) e^{-C}-1\right]\right\} \\
& \frac{C}{1} \quad \frac{F^{\prime} / F}{1.0} \\
& 1.5 \quad 0,916 \\
& 2.0 \quad 0.995 \\
& 3.01 .19
\end{aligned}
$$

The maximum deviation amounts to about a $20 \%$ overestimate for $\mathrm{C}=3,0$ which according to Loevinger (9) corresponds to a betri energy of only about 0.06 Mev, Using this linear aporoximation, the integrals above may be evaluated for more general case of arbitrary limit values why? will give rise to the manner in which the numerical machine calculations will be specified and programmed.

The 3 cases above for dose ntegrition involve two kinds of integrals which each huve to r different limit sets; accordingly, then $F$, and $F$ mat 12 heral be defined as follows: 


$$
F_{I}=\int_{\alpha}^{\beta} \int_{f(\theta)}^{g(\theta)} d J_{I} \quad F_{I I}=\int_{\alpha}^{\beta} \int_{f(\theta)}^{g(\theta)} d J_{2}
$$

where

$f(\theta)=A+B \operatorname{Sec} \theta$, and

$g(\theta)=G+H \operatorname{Sec} \theta$.

$d V(R, \theta)=2 \pi R^{2} \operatorname{Sin} \theta d \theta d R$,

wherefore,

$$
\begin{aligned}
F_{I}= & 2 \pi D_{S} R_{O}^{2} \int_{\alpha}^{\beta} d \theta \int_{f(\theta)}^{g(\theta)} \\
& \left\{\left[\mu R+T_{N} \operatorname{Sec} \theta\right]\left[e^{1-C}-1\right]+C\right\} \sin \theta d R \\
= & 2 \pi D_{S} R_{0}^{2}\left\langle\left[\frac{\mu}{2}\left(G^{2}-A^{2}\right)\left(e^{1-C}-1\right)+(G-A)\right](\cos \alpha-\cos \beta)\right. \\
+ & \left\{\left(e^{1-C}-1\right)\left[\mu(H G-A B)+T_{N}(G-A)\right]+C(H-B)\right\} \ln \left|\frac{\cos \alpha}{\cos \beta}\right| \\
+ & {\left.\left[T_{N}(H-B)+\frac{\mu}{2}\left(H^{2}-B^{2}\right)\right]\left[\frac{1}{\cos \beta}-\frac{1}{\cos \alpha}\right]\right\rangle }
\end{aligned}
$$




$$
\begin{aligned}
& F_{I I}=2 \pi D_{S} R_{0}^{2} \cdot \int_{\alpha}^{\beta} \int_{f(\theta)}^{g(\theta)}\left(\mu R+T_{N} \operatorname{Sec} \theta\right) e^{1-\left(\mu_{R}+T_{N} \operatorname{Sec} \theta\right)} \\
& \text { - } \operatorname{Sin} \theta d R \\
& =\frac{2{ }^{\pi} D_{S} R_{O}^{2}}{\mu}\left\langlee ^ { 1 - \mu _ { A } } \left\{\left(1+\mu_{A}\right)\left[\frac{\left.E_{2}\left(T_{N}+\mu B\right) \operatorname{Sec} \alpha\right)}{\operatorname{Sec} \alpha}-\frac{E_{2}\left(\left(T_{N}+\mu_{B}\right) S_{C} \beta\right)}{\operatorname{Sec} \beta}\right]\right.\right.
\end{aligned}
$$

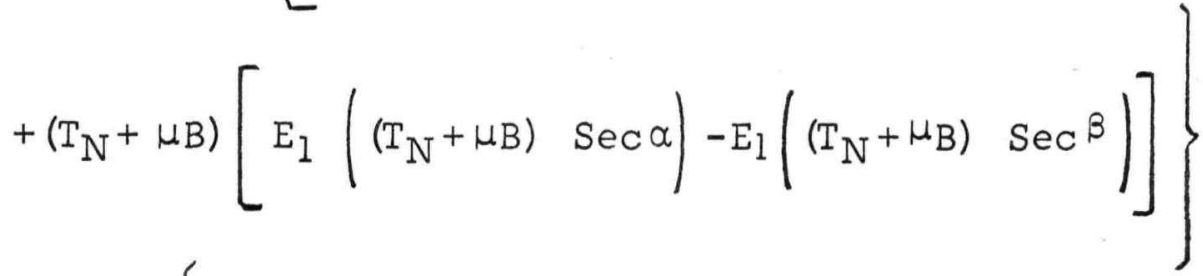

$$
\begin{aligned}
& -e^{1-\mu G}\left\{(1+\mu G)\left[\frac{\left.E_{2}\left(T_{N}+\mu H\right) \operatorname{Sec} \alpha\right)}{\operatorname{Sec} \alpha}-\frac{E_{2}\left(\left(T_{N}+\mu H\right) \operatorname{Sec} \beta\right)}{\operatorname{Sec} \beta}\right]\right. \\
& \left.\left.+\left(T_{N}+\mu H\right)\left[E_{l}\left(\left(T_{N}+\mu G\right) \sec \alpha\right)-E_{1}\left(T_{N}+\mu G\right) \sec \beta\right)\right]\right\}
\end{aligned}
$$

In the above, expansion of $E_{2}$ by integrating by parts gives,

$$
E_{2}(x)-x E_{1}(x)
$$


Numerical procedures for digital computers have been generated for evaluating $E_{I}(x)$ which can readily be applied in performing machine computation, (13) Details of the derivation of $F_{I}$ and $F_{I I}$ are given in the Appendix. The numerical procedure will involve assigning the appropriate values, to $A, B, G, H, \alpha$, and $\beta$ based upon the case, integral form (e.g., $F_{I}$ or $\left.F_{I I}\right)$ and limit parameters. A tabular listing Table 1 in the program equations summary section contains this information, which will be used in the program formulation.

\section{B. LINEAR MODEL}

A general concensus concerning penetration of beta ray penetration in matter indicates an approximate linear transmission with absorber mass for monoenergetic source energies and an exponential attenuation for sources having continuous source spectra as from radionuclides. (14) The transmission, however, is in terms of the number intensity and therefore does not take into account the spectral changes. Dose evaluation which neglects the spectrum is therefore affected since the dose or energy imparted to the media is proportional to the beta ray stopping a power which is an explicit function of energy. Two aspects of this approximate linear transmission, however, make it worthwhile, at least for purposes of this study, to briefly investigate its possible usefulness in formulating a beta dose model:

(1) the stopping power for tissue media (water taken as reference media) remains relatively constant for beta ray energies from about $0.3 \mathrm{Mev}$ up to at least $3.0 \mathrm{Mev}$, and

(2) a linear variation leads to an extremely simplified calculation.

The greatest uncertainty for the problem at hand lies in calculating the leakage or self-absorption of radiation from the particle, assuming of course that the tissue dose calculation techniques 
developed by Loevinger can be applied effectively. In this study the leakage dose at the surface of the ORNL(12) reference particle was calculated using the method described as follows.

The dose at the surface of the particle due to a volume element, $\mathrm{dV}(r)$ located a distance, $r$, from the surface is

$$
\mathrm{dD}_{\mathrm{S}}=\frac{\mathrm{Kf}(\mathrm{r})}{\mathrm{r}^{2}} \mathrm{dV}(\mathrm{r})
$$

Assuming a linear variation as far as the material is concerned allows one to write $f(r)$ as

$$
f(r)=1-\frac{r}{R_{m}}
$$

where $R_{m}$ is the maximum practical or extrapolated range of a beta particle of a particuiar energy. Using the information given in Reference (15) for the maximum range in copper (as $\bar{Z}$ for the experimental particle is about 32,5 ) enables one to write $R_{m}$ as a function of energy in the particle as follows:

$$
R_{m}=0.00762 \frac{\rho_{p}}{\rho_{\mathrm{cu}}}\left(\frac{E}{0.3}\right)^{1.3} \mathrm{~cm}
$$

where

$$
\begin{aligned}
& \rho_{p}=\text { Particle density, } 2.64 \mathrm{gm} / \mathrm{cm}^{3}, \\
& \rho_{\mathrm{Cu}}=\text { Copper density, } 8,92 \mathrm{gm} / \mathrm{cm}^{3} .
\end{aligned}
$$

Using the same geometry given in Figure 5 for determining the spherical particle surface dose, $D_{S}$ is given as

$$
\begin{aligned}
D_{S} & =k \int_{0}^{R_{m}} \quad \frac{r}{2} 2 \pi r^{2}\left[1-\frac{r}{2 R_{0}}\right] d r \\
& =\frac{\pi k R_{m}}{6 R_{O}}\left(5 R_{0} \cdots R_{m}\right)
\end{aligned}
$$


The constant, $\mathrm{K}$, is the same as given in section III-A-l above for exponential attenuation.

Again using the ORNL particle and source data, six beta ray energy group calculations give $\sim 445 \mathrm{Rad} / \mathrm{hr}$ for $\mathrm{D}_{\mathrm{S}}$ and $\sim 235$ $\mathrm{Rad} / \mathrm{hr}$ for the average dose, $\overline{\mathrm{D}}_{\mathrm{S}}$. The assummed energies, maximum beta ranges, and individual doses are tested below for the six beta ray energy groups.

\begin{tabular}{cllc}
$\begin{array}{c}\text { upper limit } \\
\text { of interval } \\
(\mathrm{Mev})\end{array}$ & $\begin{array}{c}\text { Average of } \\
\text { interval } \\
\text { (Mev) }\end{array}$ & $\begin{array}{l}\text { Maximum } \\
\text { Range, cm } \\
R_{m}\end{array}$ & $\begin{array}{c}\text { Surface } \\
\text { Dose Ra } \\
\text { Rad/hr }\end{array}$ \\
\cline { 2 - 3 } 0.1 & 0.05 & & \\
0.3 & 0.2 & 0.00635 & 28.4 \\
0.6 & 0.4 & 0.02577 & 37.9 \\
0.9 & 0.7 & 0.0634 & 100.15 \\
1.1 & 1.0 & 0.1072 & 137.1 \\
1.5 & 1.75 & 0.14 & 75.8 \\
& & 0.2085 & $\underline{65.6}$ \\
\hline 44.95
\end{tabular}

C. TRANSPORT MODEL

A brief investigation was made concerning the use of transport methods for application to the beta particle dose determination. Transport theory is attractive for this purpose since both the spatial and energy distributions of beta particle interactions $\mathrm{w}$ ith matter are treated and the geometry of the physical model is regular.

Transport theory has been applied to beta radiation in work described by Spencer (4), in which he calculated energy dissipation functions using machine computations to solve the transport equation by obtaining the spatial moments. Energy dissipation functions were obtained for several single media, all considered homogeneous and infinite. Application of Spencer's data to the problem at hand either for determining the surface leakage dose from the particle or the dose distribution in tissue is possible; however, the latter la catur knowledge of the beta ray spectra and directud the bounday. Some feeling 
for the agreement of these transport calculations with experimental data and other methods can bje gained by calculating the dose at the surface of the ORNL particle using the energy dissipation functions $\mathrm{J}(\mathrm{x})$ generated for single homogeneous media by Spencer(4)。

Using the $1 \mathrm{~cm} O \mathrm{ONI}$ particle $\left(\mathrm{UO}_{2}-\mathrm{C}\right.$, Sr-89) with a density of $2.64 \mathrm{gm} / \mathrm{cm}^{3}$ and an estimated average atomic number, $Z$ 。 of 32.5 , requires an appropriate extrapolation of Spencer's data. The material for which energy dissipation data are given which bracket $Z=32.5$, are copper; $Z=29$, and tin; $Z=50$, Values for the energy dissipation function $y(x)$ for $Z=32.5$ were determined by assuming a linear variation in $Z$ of the fu function,

$$
f(x, z)=\frac{1}{A(Z)} \quad \ln J(x, z)
$$

to obtain

$$
g(x, z)=f(x, 29)+\frac{f(x, 50)-f(x, 29)}{(50-29)} z, 29 \leq z \leq 50
$$

and then

$$
g(x, 32,5)
$$

Values of $A(Z)$, the residual beta range; $r_{0}(Z)$, and the stopping power; $(-d E / d x)$ Eo, were all obtained graphically for $Z=32.5$, by, cross plotting these quantities as a function of $Z$ for each particular beta source energy, $E_{O}$. The energy dissipation function for $Z=32.5$ is then given by

$$
J(x, 32,5)=e^{A(32,5) g(x, 32,5)}
$$

The isotropic point source data given by Spencer may be defined in terms of the amount of energy dissipated within a spherical shell located a distance between $r$ and $r+d r$ from a point isotropic source of beta rays of energy $E_{O}, i_{0} e_{0}$,

$$
\left[-\frac{d E}{d r}\right]_{E_{O}} \text { J J ridr Mev }
$$

If it is assumed that the energy dissipation distribution in the media $J(r)$ describes the local energy absorption distribution 
(i.e., disregarding the photon production and absorption) a dose relationship can be formulated for calculating the source leakage dose at the particle surface. The differential dose rate, $d D_{E_{O^{\prime}}}$ at the surface of a homogeneously distributed shperical volume source may be given as

$$
\begin{aligned}
& d D_{E_{0}}=\frac{S_{E_{0}} K \varepsilon(r)}{4 \pi}\left[\begin{array}{l}
d E \\
d r
\end{array} E_{O}\right. \\
& \mathrm{xJ}(\mathrm{r}) \frac{\mathrm{dV}(\mathrm{r})}{\mathrm{r}^{2}} \quad \frac{\mathrm{rad}}{\mathrm{hr}}
\end{aligned}
$$

where

$$
\begin{aligned}
& \begin{aligned}
S_{E_{0}}= & \text { volume source of betas of energy, } E_{O} \\
& \left(B / \mathrm{sec}^{\left.-\mathrm{Cm}^{3}\right)}\right.
\end{aligned} \\
& \mathrm{K}=\mathrm{constan} t=\frac{\left(1.602 \times 10^{-6}\right)(3600)}{100} \\
& =5.76 \times 10^{-5} \frac{\mathrm{gm}-\mathrm{rad}-\mathrm{sec}}{\mathrm{Mev}-\mathrm{hr}} \\
& {\left[-\frac{d E}{d r}\right]_{E_{O}}=\begin{array}{l}
\text { stopping power for beta ray energy, } \\
\text { for the particle。 } Z=32.5\left(\mathrm{Mev}-\mathrm{cm}^{2} / \mathrm{gm}\right)
\end{array}} \\
& \varepsilon(r)=\frac{}{T^{(-d E / d r)} E(r)} \quad / \frac{}{P^{(-d E / d r)} E(r)} \\
& \bar{T} \overline{(d E / d r)}=\begin{array}{l}
\text { effective average stopping power in tissue for } \\
\text { a beta leakage spectra distribution in terms }
\end{array} \\
& \text { of a distance, } r \text {, from a point beta source in } \\
& \text { the particle media. } \\
& \overline{\mathrm{P}^{(\mathrm{dE} / \mathrm{dr})} \mathrm{E}(\mathrm{r})}=\begin{array}{l}
\text { effective beta stopping power in the particle } \\
\text { media for same conditions given above for tis sue }
\end{array}
\end{aligned}
$$


The value of $s(r)$ changes owing to the slowing down spectral changes of the electrons with distance from the source.

However, it can be shown that this change is only very slight with beta energy, and therefore in $r$, the variable of integration here. This is illustrated by the data of Nelms(16) in which it is suggested that the stopping power for mixtures can be obtained approximately by mass-wrighting the constituent stopping powers, accordingly for the $\mathrm{UO}_{2}-\mathrm{C}$ ORNL particle:

$$
\left(-\frac{d E}{d X}\right)_{P}=0.362\left(-\frac{d E}{d X}\right)_{U}+0.419\left(-\frac{d E}{d X}\right)_{O}+0.6519\left(-\frac{d E}{d X}\right)_{C}
$$

Using the stopping powers for water to approximate those of tissue, comparisons can be made from the listing in Table 2 below:

TABLE 2

COMPARISON OF STOPPING POWERS*

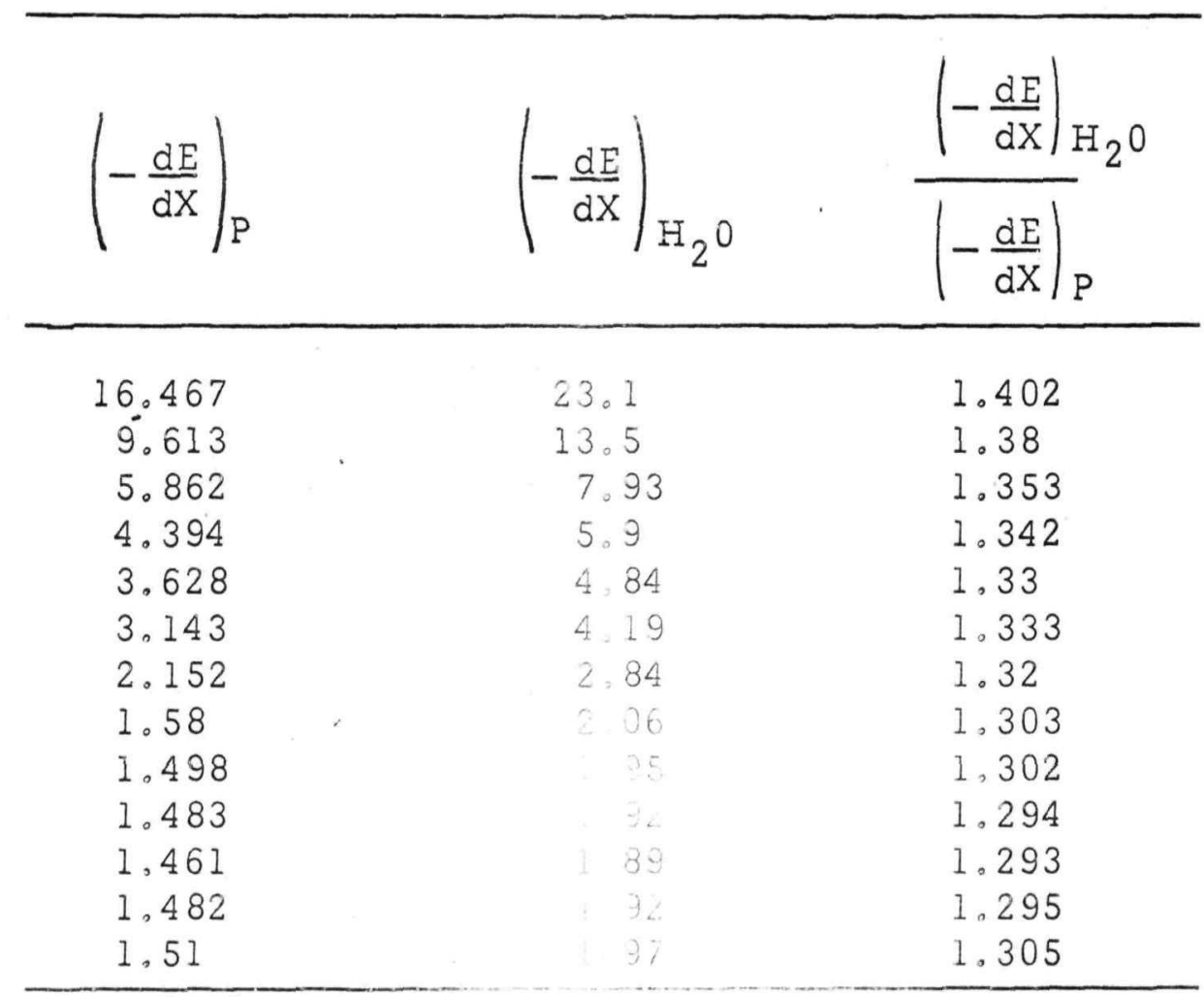

*Data from Nelms, National Bureau of Standards Circular, No, 577 . 
A reasonable average for $\epsilon(r)$ a ppears to be about 1.33 since over a considerable range of energies ranging from $0.01 \mathrm{Mev}$ to at least $2.8 \mathrm{Mev}$, the ratio of stopping powers remains relatively constant. This assumption vastly simplifies this specific analysis allowing integration over the variable, $r$, without having to determine the effective average stopping power otherwise given by:

$$
\left(-\frac{d E}{d r}\right)_{E(r)}=\frac{\int_{0}^{E_{O}}\left(-\frac{d E}{d r}\right) E(r) I(E, r) d E}{\int_{O}^{E_{O}} I(E, r) d E}
$$

where I $(E, r)$ is the beta ray spectra after penetration of a distance $r$. Values for the energy dissipation function are actually given in terms of the residual range $x=r / r_{0}$, for which,

$r=\int_{0}^{E}\left(-\frac{d E^{\prime}}{d E}\right)$

(Continuous slowing down approximation)

Using the geometry given in Figure 5 for determining the leakage dose at the particle surface, the beta dose integral may be formed by first writing.

$J(x) d V(r)=\frac{I(x)}{r^{2}} \quad 2 \pi r^{2}\left(I-\frac{r}{2 R_{0}}\right) d r$

$=2 \pi\left[J(x) d r-\frac{1}{2 R_{0}} r J(x) d r\right]$

For $r$ and $r{ }^{\prime} \circ$ designed as having linear dimensions

$d V(r)=2 \pi\left[r_{0}^{\prime} J(x) d x-\frac{r_{0}^{\prime}{ }^{2}}{2 R_{0}}-x J(x) d x\right]$. 
Now for $r_{0}^{\prime}=\frac{r_{0}}{\rho}$, where $r_{0}$ is the mass distance, $\mathrm{gm} / \mathrm{cm}^{2}$ the dose may be given as

$$
d D_{E_{O}}=\frac{S_{E_{O}}}{2} K\left(-\frac{d E}{d r}\right)_{E_{O}}\left[\frac{r_{O}}{\rho} J(x) d x-\frac{r_{O}{ }^{2}}{2 R_{O} \rho^{2}} \quad x J(x) d x\right]
$$

and

$D_{E_{O}}=\frac{S_{E_{O}}}{2} K\left(-\frac{d E}{d r}\right)_{E_{O}}\left\{\frac{r_{O}}{\rho} \int_{0}^{X} j(x) d x-\frac{r_{O}^{2}}{2 R_{O} \rho^{2}} \int_{0}^{X} x J(x) d x\right\}$

where

$$
\begin{aligned}
\rho & =2.64 \mathrm{gm} / \mathrm{cm}^{3} \\
R_{O} & =0.5 \mathrm{~cm} \\
X & =1, r\left(E_{O}\right)>R_{O} \\
& =\frac{R_{O}}{r_{O}^{\prime}}, r\left(E_{O}\right)>R_{O}
\end{aligned}
$$

For these calculations, $r\left(E_{O}\right)<R_{O}$, and $X=1$, and then since

$$
\int_{0}^{1} J(x) d x=\frac{\left(\frac{E_{O}}{r_{O}}\right)}{\left(-\frac{d E}{d r}\right)_{E_{O}}}
$$

The dose may be written as

$$
D_{E_{O}}=\frac{S_{E_{O}}}{2} K\left[\frac{E_{O}}{\rho}-\left(-\frac{d E}{d r}\right)_{E_{O}} \frac{r^{\prime}{ }^{2}}{2 R_{O}} \int_{O}^{l} x J(x) d x\right]
$$

The above integration was performed graphically by first plotting $\mathrm{xJ}(\mathrm{x})$ against $\mathrm{x}$ as shown in Figure 7 and then using a planimeter. Six beta ray group energy calculations were performed to obtain a value of approximately $150 \mathrm{rad} / \mathrm{hr}$ for the leakage dose average over $1 \mathrm{~cm}^{2}$ of surface area; this value agrees very well with the reported measured value shown in Figure 1. Some pertinent values of the calculation are summarized in the below listing. 


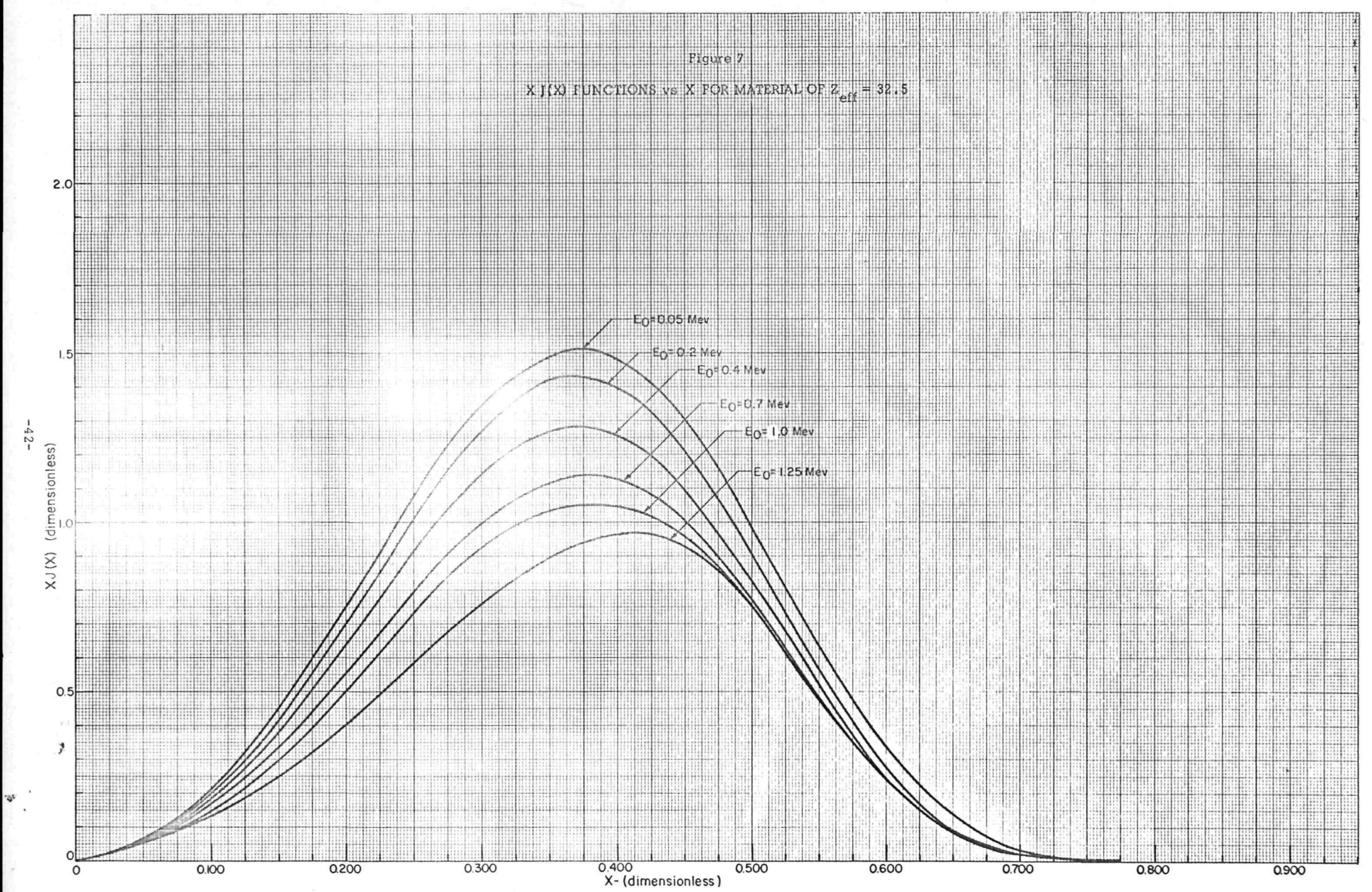




\begin{tabular}{|c|c|c|c|c|}
\hline $\begin{array}{c}\text { Beta Source } \\
\text { Energy } \\
E_{\circ}(\mathrm{Mev})\end{array}$ & $\begin{array}{c}{\left[-\frac{d E}{d r}\right]_{E_{O}}} \\
\left(\mathrm{Mev} / \mathrm{cm}^{2} / \mathrm{gm}\right)\end{array}$ & $\begin{array}{l}\text { Residual } \\
\text { Range } \\
r_{0}(\mathrm{~cm})\end{array}$ & $\begin{array}{c}S_{E_{O}} \\
\left(Q / \sec -\mathrm{cm}^{3}\right)\end{array}$ & $\begin{array}{c}D_{E_{O}} \\
(\mathrm{Rad} / \mathrm{hr} .)\end{array}$ \\
\hline 0.05 & 4.16 & 0.00269 & $3.72 \times 10^{6}$ & 1.964 \\
\hline 0.20 & 1.83 & 0.0 .65 & $8.99 \times 10^{6}$ & 19.43 \\
\hline 0.40 & 1.41 & 0.075 & $1,49 \times 10^{7}$ & 63.61 \\
\hline 0.70 & 1.30 & 0.173 & $1.36 \times 10^{7}$ & 98.00 \\
\hline 1.00 & 1.26 & 0.246 & $6.72 \times 10^{6}$ & 68.14 \\
\hline 1.25 & 1.24 & 0.314 & $3.95 \times 10^{6}$ & $\frac{36.72}{287.864}$ \\
\hline
\end{tabular}




\section{BIBLIOGRAPHY}

1. Couchman, M.I。, et. a . "NTRSE-1, A Nuclear Rocket Safety Evaluation Code for the Control Data 3600," NUS180, (December, 1964.

2. Fishi, B.R。, et。al。, "Envromental Studies: Radiological Significance of Nuclear Rocket Debris," Semiannual Progress Report for Period from July 1, 1964 to December 1,1964 (to be published)

3. Berger, M.J., NBS, private communication

4. Spencer, I.V., "Energy Dissipation by Fast Electrons" NBS Monograph \#1, (September 10, 1959)

5. Rutherford, E., Phil. Mäg. 47, 116 (1899)

6. Mott, N.F., Proe. Roy. Soc., Londoni A 124425 (1929)

7. Rossi, H。H。, and Ellis, R。H., Ir。 "Distributed Beta Sources in Uniformly Absorbing Media" Nucleonics 7, No.1, 18 (1950); 7, No.2, 19 (1950)

8. Hine, $G_{0} J_{0}$, and Brownell, G。 L。, Radiation Dosimetry, Academic Press, Inc。, NoY。(1956)

9. Evans, R.D。, The Atomic Nuclear, McGraw Hill Book Co., Inc. (1955)

10. Brownell。G.L。, "Interaction of Phosphorus-32 Beta Rays with Matter," Nucleonics 10, No.6, January, 1952

11. Berger, M.Jo, and Seltzer, S. Mo, "Tables of Energy Losses and Ranges of Electrons and Positrons," NASA SP-3012, (1964)

12. Hogan, O.H. et. al., "Beta Spectra, Spectra of Individual Negitron Emitters," USNRDL-TR-802, 16 December, 1964 
13. Abramowitz, M. and Stegun, I。A., eds., Handbook of Mathematical Functions, NBS Applied Mathematics Series 55, June, 1964, U.S.Govt.Printing Office, Wa shington, D。C。

14. Bleuler, E。 and Goldsmith, G。J , Experimental Nucleonics, Rinehart \& Company, Inc., New York (1952)

15. Kinsman, $S_{\circ}$, ed。, Radiological Health Handbook, Division of Radiological Health, Department of Health, Education and Welfare, Revised edition, 1960 .

16. Nelms, A.T., "Energy Loss and Range of Electrons and Positrons," NBS circular 577, July 26, 1956. 
I. DIFFERENTIAL VOLUME OF INTEGRATION

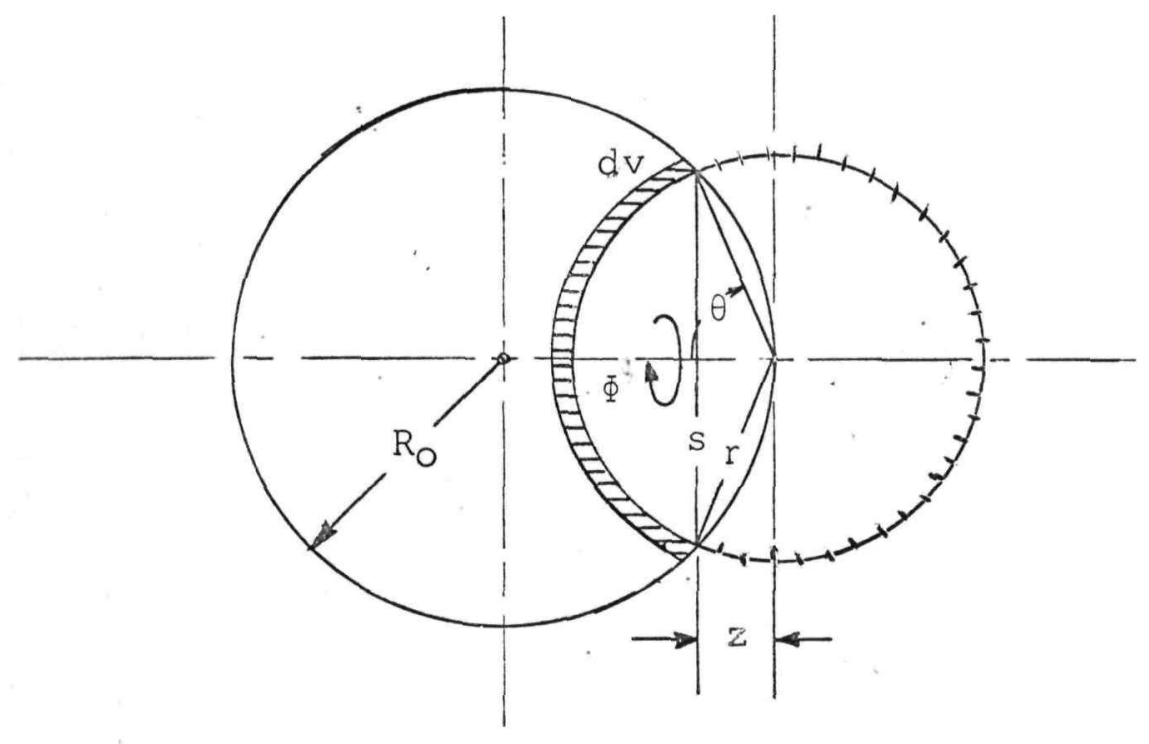

$$
\begin{aligned}
d v & =s d \Phi r d \theta d r, \quad s=r \sin \theta \\
& =2 \pi r^{2} d r \sin \theta d \theta
\end{aligned}
$$

$$
\begin{aligned}
& =2 \pi r^{2} d r \int_{0}^{\theta(r)} \sin \theta d \theta \\
& =2 \pi r^{2} d r[1-\cos \theta(r)]
\end{aligned}
$$


Now,

$$
x^{2}+y^{2}+\left(z-R_{0}\right)^{2}=R_{o}^{2} \quad R_{o}^{2}-\left(z-R_{O}\right)^{2}=r^{2}-z^{2}
$$

and

$$
\begin{aligned}
& x^{2}+y^{2}+z^{2}=r^{2} \\
& 2 z R_{0}=r^{2} \quad r=\frac{r^{2}}{2 R_{0}} \\
& \cos \theta(r)=\frac{z}{r}=\frac{\left(\frac{r^{2}}{2 r_{0}}\right)}{r}=\frac{r}{2 R_{O}}
\end{aligned}
$$

so,

$$
d v(r)=2 \pi r^{2}\left[1-\frac{r}{2 R_{O}}\right] d r
$$

II. INTENSITY FROM SPHERICAL SURFACE SOURCE

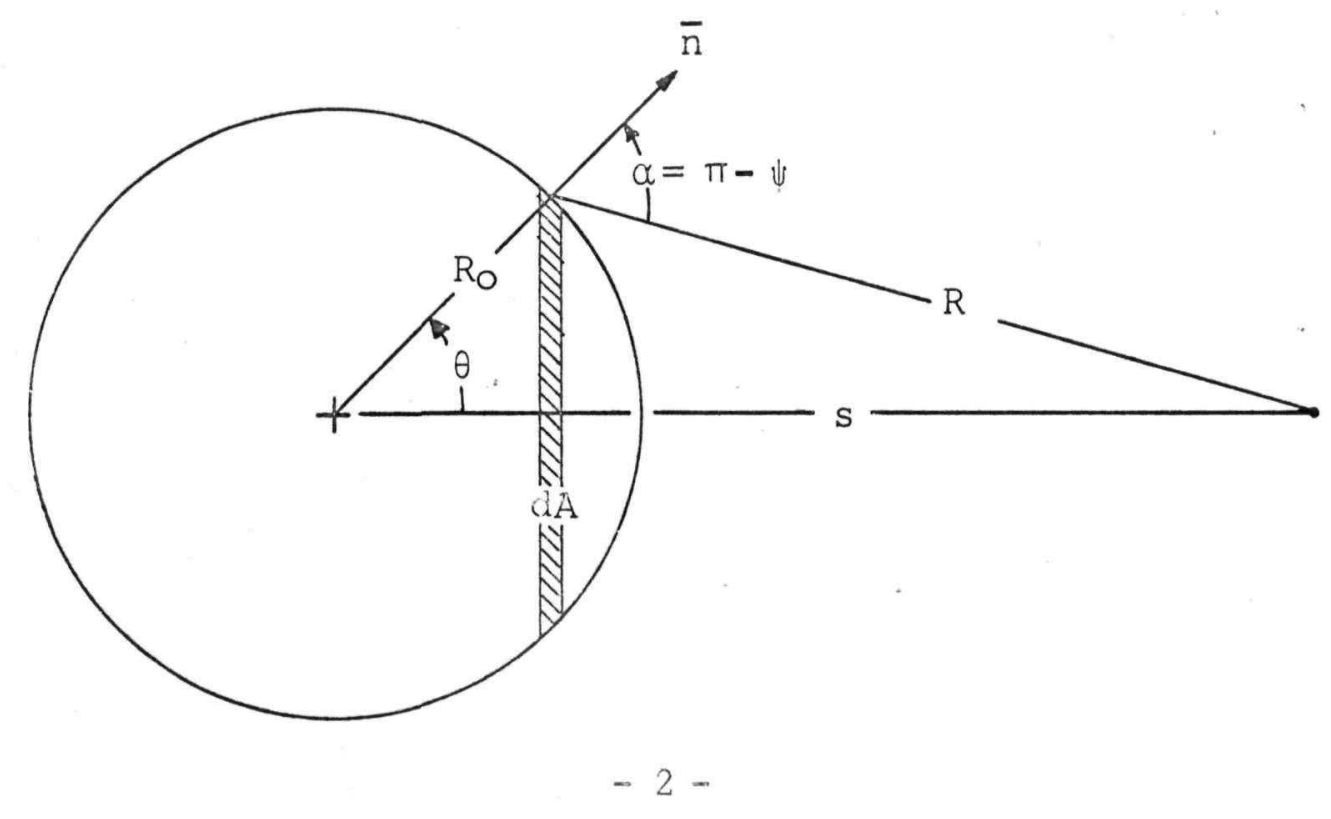


The intensity, I, a distance s from the sphere center

$$
\begin{gathered}
I=\int_{A} f(R) d A=2 \pi R_{0}^{2} \int_{0}^{\cos ^{-1}\left(\frac{R_{O}}{S}\right)} f(R) \sin \theta d \theta \\
R^{2}=R_{0}^{2}+s^{2}-2 R_{O} s \cos \theta \\
2 R d R=2 R_{O} s \sin \theta d \theta
\end{gathered}
$$

$$
\sin \theta d \theta=\frac{R d R}{R_{0} S}
$$

for

$$
f(R)=\frac{1}{4 \pi R^{2}}, \text { I is rewiliten as }
$$

$$
I=\frac{R_{0}}{2 S} \int_{S-R_{O}}^{\sqrt{s^{2}-R_{O}^{2}}} \cos \alpha \frac{d R}{R}
$$

now

$$
s^{2}=R_{0}^{2}+R^{2}-2 R_{0} R \cos \psi
$$




$$
\cos \psi=\frac{R_{0}^{2}+R^{2}-s^{2}}{2 R_{0} R}
$$

$$
\cos \alpha=\cos (\pi-\psi)=-\cos \psi
$$

$-\cos \psi=-\frac{2{ }_{0}^{2}+R_{O}^{2}+s^{2}-2 R_{o} s \cos \theta-s^{2}}{2 R_{O} R}$

$$
=-\frac{2 R_{O}^{2}-2 R_{O} S \cos \theta}{2 R_{O} R}
$$

$$
=-\frac{2 R_{O} S \cos \theta-2 R_{O}^{2}}{2 R_{O} R} \cos \alpha
$$

with,

$$
\begin{aligned}
2 R_{0} s \cos \theta=\left(R_{0}^{2}+s^{2}\right)-R^{2} \\
\cos \alpha=\frac{R_{0}^{2}+s^{2}-2 R_{0}^{2}}{2 R-2)} \\
=\frac{\left(s^{2}-R_{O}^{2}\right)-R^{2}}{2 R_{O} R}
\end{aligned}
$$


and the intensity is

$$
I=\frac{1}{4 s} \int_{S-R_{0}}^{\sqrt{s^{2}-R_{O}^{2}}} \frac{\left(s^{2}-R_{O}^{2}\right)-R^{2}}{R^{2}} d R
$$

$$
=\frac{1}{4 s}\left\{\left(s^{2}-R_{0}^{2}\right) \int_{S-R_{0}}^{\sqrt{s^{2}-R_{O}^{2}}} \frac{d R}{R^{2}}-\int_{S-R_{0}}^{\sqrt{s^{2}-R_{O}^{2}}} d R\right\}
$$

$$
=\frac{1}{4 s}\left\{\left(s^{2}-R_{0}^{2}\left[\frac{1}{(s-j)}\right]\right.\right.
$$

$$
\left.\begin{array}{l}
\left.+\left(s-R_{0}\right)-\sqrt{s^{2}-R_{0}^{2}}\right\} \\
=\frac{1}{4 s}\left\{s+R_{0}-\sqrt{s^{2}-R_{0}^{2}}+\left(s-R_{0}-\sqrt{s^{2}-R_{0}^{2}}\right.\right.
\end{array}\right\}
$$




$$
\begin{aligned}
& =\frac{1}{2 s}\left[s-\sqrt{s^{2}-R_{0}^{2}}\right] \\
& =\frac{1}{2}\left\{1-\sqrt{1-(s)^{2}}\right\}
\end{aligned}
$$

The above is for a unit source strength. $s_{a}=1$.

\section{SPHERICAL SHELL VOLUME, $V_{k}$}

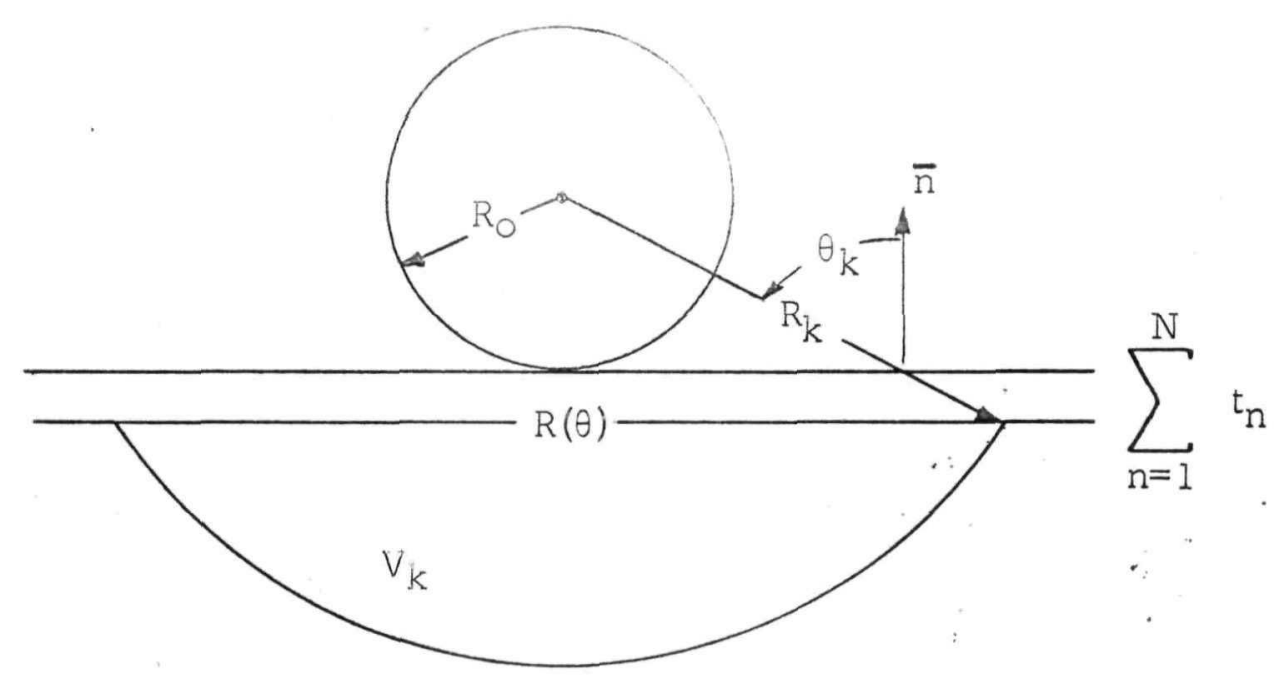

$$
d V=2 \pi r^{2} \sin \theta d \theta d r
$$




$$
V_{k}=\frac{2 \pi}{3}\left[\frac{S_{N}^{3}}{2} \tan ^{2} \theta_{k}+R_{k}^{3}\left(\cos \theta_{k}-1\right)\right]
$$

IV. INTEGRATION ZONE AND REGION LIMITS

Referring to the dose model shown in Figure 5 of the text,

$$
X(R, \theta)_{i}=C_{i}=\mu_{i} R+T_{N i} \sec \theta
$$

for $\theta=0$

$$
\begin{gathered}
\mu_{i} R_{I}+T_{N i}=C_{i} \\
R_{I i}=\frac{C_{i}-T_{N i}}{\mu_{i}} \\
\theta_{I i}=\cos ^{-1}\left(\frac{S_{N}}{R_{I i}}\right), S_{N}=R_{0}+\sum_{n=1}^{N} t_{n}
\end{gathered}
$$

The boundary surface $\ell_{i}(\theta)$ and $R(\theta)$ are

$$
\begin{aligned}
& l_{i}(\theta)=R_{I i}+R_{O}(\sec \theta-1), \\
& R(\theta)=S_{N} \sec \theta
\end{aligned}
$$


${ }^{\theta}$ IIi is obtained by equating $\ell_{i}(\theta)$ and $z(\theta), i, e .$,

$$
\mathrm{R}_{I i}+\mathrm{R}_{\mathrm{O}}\left(\sec \theta_{I I i^{-}}\right)=\mathrm{S}_{\mathrm{N}} \sec \theta_{I I i}
$$

giving ,

$$
\theta_{I I i}=\sec ^{-1}\left[\frac{R_{I i}-R_{0}}{S_{N}-R_{O}}\right]
$$

and, .

$$
R_{I I i}=S_{N} \sec \theta_{I I i}=\frac{S_{N}\left(R_{I i}-R_{O}\right)}{S_{N}-R_{O}} .
$$

When $\sum_{n=1}^{N} t_{n}=0, S_{N}=R_{0}$, and $\theta_{I I i}$ and $R_{I I i} \longrightarrow \infty$,

and are therefore not defined for these calculations when no absorbers are present.

A radial vector, $\overrightarrow{\mathrm{R}}_{\mathrm{k}}$, is specified for an integration limit for

$$
\left|\vec{R}_{k}\right|>\left(R_{\circ}+\sum_{n=1}^{N} t_{n}\right)
$$

for which,

$$
\theta_{k}=\cos ^{-1} \frac{S_{N}}{R_{k}} \text {, where }\left|\vec{R}_{k}\right|=R_{k} .
$$


The angle of intersection, $\theta_{k x}$, (where $R_{k} \geq R_{I}$ ) is given when

$$
\ell_{i}\left(\theta_{k x}\right)=R_{k}=R_{I i}+R_{0}\left(\sec \theta_{k x}-1\right),
$$

yielding

$$
\sec \theta_{k x}=\frac{R_{k}-R_{I i}}{R_{0}}+1
$$

and

$$
\theta_{k x}=\sec ^{-1}\left[\frac{R_{k}+R_{o}-R_{I i}}{R_{0}}\right]
$$

V. INTEGRAL DOSE FUNCTIONS。. FI AND F II

First consider $\mathrm{F}_{\mathrm{I}}$ :

$F_{I}=2 \pi D_{S} R_{0}^{2} \int_{\alpha}^{B} d \theta \int_{f(\theta)}^{J(\theta)}\left[\mu R+T_{N} \sec \theta\right]\left[\left(e^{I-C}-1\right)+C\right] \sin \theta d R$

where,

$$
g(\theta)=G+H \sec \theta
$$

and,

$$
f(\theta)=A+B \sec \theta
$$


First consider:

$$
\int_{\alpha}^{\beta} d \theta \int_{f(\theta)}^{g(\theta)} C \sin \theta d R=C \int_{\alpha}^{\beta} \sin \theta d \theta[g(\theta)-f(\theta)]
$$

where

$$
[g(\theta)-f(\theta)]=(G-A)+(H-B) \sec \theta
$$

then,

$$
(G-A) \int_{\alpha}^{\beta} d \theta \sin \theta=(G-A)(\cos \alpha-\cos \beta)
$$

and,

$$
\begin{aligned}
(H-B) \int_{\alpha}^{\beta} d \theta \sec \theta \sin \theta & =(H-B) \int_{\alpha}^{\beta} \tan \theta d \theta \\
& =(H-B) \ln \left|\frac{\cos \alpha}{\cos \beta}\right|
\end{aligned}
$$


So that

$$
\begin{aligned}
\int_{\alpha}^{\beta} d \theta & \int_{f(\theta)}^{g(\theta)} C \sin \theta d R \\
& =C\left[(G-A)(\cos \alpha-\cos \beta)+(H-B) \ln \left|\frac{\cos \alpha}{\cos \beta}\right|\right]
\end{aligned}
$$

Now consider:

$$
\begin{aligned}
& \int_{\alpha}^{\beta} d \theta \int_{f(\theta)}^{g(\theta)}\left(e^{1-C}-1\right)\left(\mu R+T_{N} \sec \theta\right) \sin \theta d R \\
& \int_{f(\theta)}^{g(\theta)} R d R=\left.\frac{\mu R^{2}}{2}\right|_{f(\theta)} ^{g(\theta)}=\frac{\mu}{2}\left\{[g(\theta)]^{2}-[f(\theta)]^{2}\right\} \\
= & \frac{\mu}{2}\left[G^{2}+2 H G \sec \theta+H^{2} \sec ^{2} \theta-A^{2}-2 A B \sec ^{2} \theta-B^{2} \sec ^{2} \theta\right] \\
= & \frac{\mu}{2}\left[\left(G^{2}-A^{2}\right)+2(H G-A B) \sec ^{2} \theta+\left(H^{2}-B^{2}\right) \sec ^{2} \theta\right]
\end{aligned}
$$


also,

$$
\begin{aligned}
& \mathrm{T}_{\mathrm{N}} \sec \theta \int_{\alpha}^{\beta} \mathrm{d} \theta \int_{\mathrm{f}(\theta)}^{\mathrm{J}(\theta)} \mathrm{dR}=\mathrm{T}_{\mathrm{N}} \sec \theta[(\mathrm{G}-\mathrm{A})+(\mathrm{H}-\mathrm{B}) \sec \theta] \\
& \quad=\mathrm{T}_{\mathrm{N}}\left[(\mathrm{G}-\mathrm{A}) \sec \theta+(\mathrm{H}-\mathrm{B}) \sec ^{2} \theta\right],
\end{aligned}
$$

then

$$
\begin{gathered}
\int_{\alpha}^{\beta} d \theta \int_{f(\theta)}^{g(\theta)}\left(\mu R+T_{N} \sec \theta\right) \sin \theta d R \\
\left.=\int_{\alpha}^{B}\left[\begin{array}{l}
\frac{\mu}{2}\left(G^{2}-A^{2}\right)+\left[\mu(H G-A B)+T_{N}(G-A)\right] \sec \theta \\
T_{N}(H-B)+\frac{\mu}{2}\left(H^{2}-B^{2}\right)
\end{array}\right] \sec ^{2} \theta\right\} \sin \theta d \theta
\end{gathered}
$$

Integrating,

$$
\int_{\alpha}^{\beta} \sin \theta d \theta=(\cos \alpha-\cos \beta)
$$


and

$$
\int_{\alpha}^{\beta} \sec \theta \sin \theta d \theta=\int_{\alpha}^{\beta} \tan d \theta=\ln \left|\frac{\cos \alpha}{\cos \beta}\right|
$$

and

$$
\begin{aligned}
\int_{\alpha}^{\beta} \sec ^{2} \theta \sin \theta d \theta & =\int_{\alpha}^{\beta} \sec \theta \tan \theta=\left.\sec \theta\right|_{\alpha} ^{\beta} \\
& =(\sec \beta-\sec \alpha) .
\end{aligned}
$$

Multiplying by the appropriate coefficients, we may write:

$$
\begin{aligned}
F_{I}= & 2 \pi D_{S} R_{O}^{2}\left\{\left(\frac{\mu}{2}\left(G^{2}-A^{2}\right)\left(e^{1-C}-1\right)+C(G-A)\right)(\cos \alpha-\cos \beta)\right. \\
& \left.+\left[\left(e^{1-C}-1\right)\left(\mu(H G-A B)+T_{N}(G-A)\right)+C(H-B)\right] \ln \left|\frac{\cos \alpha}{\cos \beta}\right|\right) \\
& \left.+\left(T_{N}(H-B)+\frac{\mu}{2}\left(H^{2}-B^{2}\right)\right)\left(\frac{1}{\cos \beta}-\frac{1}{\cos \beta}\right)\right\}
\end{aligned}
$$


Now consider $F_{I I}$ :

$$
F_{I I}=2 \pi D_{S} R_{O}^{2} \int_{\alpha}^{\beta} d \theta \int_{f(\theta)}^{g(\theta)}\left(\mu R+T_{N} \sec \theta\right) e^{l-\left(\mu R+T_{N} \sec \theta\right)} \sin \theta d R
$$

first

$$
\begin{aligned}
\int_{f(\theta)}^{g(\theta)} & \left(\mu R+T_{N} \sec \theta\right) e^{-\left(\mu R+T_{N} \sec \theta\right)} \sin \theta d R \\
& =\sin \theta e^{-T_{N} \sec \theta} \int_{f(\theta)}^{g(\theta)}\left(\mu R+T_{N} \sec \theta\right) e^{-\mu R} d R .
\end{aligned}
$$

Integration in $\mathrm{R}$ gives:

$$
\begin{gathered}
\frac{1}{\mu}\left\{e^{-\mu f(\theta)}[1+\mu f(\theta)]-e^{-\mu g(\theta)}[1+\mu g(\theta)]\right. \\
\left.+T_{N} \sec \theta\left[e^{-\mu f(\theta)}-e^{-\mu g(\theta)}\right]\right\}
\end{gathered}
$$

where for

$$
f(\theta)=A+B \sec \theta
$$

and

$$
g(\theta)=G+H \sec \theta
$$


We have,

$$
\begin{aligned}
& \left\{e^{-A \mu} \cdot e^{-\mu B \sec \theta}[1+\mu A+\mu B \sec \theta]-e^{-G \mu} \cdot e^{-H \mu \sec \theta}[1+\mu G+\mu H \sec \theta]\right. \\
& \left.+T_{N} \sec \theta\left(e^{-\mu A} \cdot e^{-\mu B} \sec \theta-\mu G \quad-\mu H \sec \theta\right)\right\} \ldots \\
& =\left[e^{-\mu A} \cdot e^{-\mu B \sec \theta}(I+\mu A)+e^{-\mu A} \cdot e^{-\mu B \sec \theta} \mu B \sec \theta\right. \\
& e^{-\mu G} \cdot e^{-\mu H \sec \theta}(I+\mu G)-e^{-\mu G} \cdot e^{-\mu H \sec \theta} \mu H \sec \theta \\
& \left.+\mathrm{T}_{N} e^{-\mu \mathrm{A}} \sec \theta e^{-\mu B \sec \theta}-\mathrm{T}_{N} e^{-\mu \mathrm{G}} \sec \theta e^{-\mu \mathrm{G} \sec \theta}\right]
\end{aligned}
$$

The second integration is in $\theta$ so that the functions and their coefficients may be written as follows:
FUNCTION
COEFFICIENT
1) $e^{-\left(T_{N}+\mu B\right) \sec \theta}$
$+e^{-\mu A}(1+\mu A)$
2) $e^{-\left(\mathrm{T}_{N}+\mu \mathrm{H}\right) \sec \theta}$
$-e^{-\mu G}(1+\mu G)$
3) $e^{-\left(T_{N}+\mu B\right) \sec \theta} \cdot \sec \theta$
$+e^{-\mu \mathrm{A}}\left(\mathrm{T}_{\mathrm{N}}+\mu \mathrm{B}\right)$
4) $\mathrm{e}^{-\left(\mathrm{T}_{\mathrm{N}}+\mu \mathrm{H}\right) \sec \theta} \cdot \sec \theta$
$-e^{-\mu G}\left(T_{N}+\mu G\right)$ 
Functions (1) and (2) above, when integrated, have the form:

$$
\begin{aligned}
& \int_{\alpha}^{\beta} e^{-k \sec \theta} \sin \theta d \theta=k \int_{k \sec \alpha}^{k \sec \beta} \frac{e^{-u}}{u^{2}} d u \\
& =\left[\frac{E_{2}(k \sec \alpha)}{\sec \alpha}-\frac{E_{z}(k \sec \beta)}{\operatorname{se}}\right]
\end{aligned}
$$

Functions (3) and (4) above, whentegrated have the form:

$$
\begin{gathered}
\int_{\alpha}^{\beta} e^{-k \sec \theta} \sec \theta \sin \theta d \theta=\int_{k \sec \alpha}^{k \sec \beta} \frac{e^{-u}}{u} d u \\
\quad=\left[E_{1}(k \sec \alpha)-E_{1}(k \sec \beta)\right]
\end{gathered}
$$


Making the proper substitutions from above, we obtain for $F_{I I}$,

$$
\begin{aligned}
& F_{I I}=\frac{2 \pi D_{S} R_{0}^{2}}{\mu}\left\{e ^ { 1 - \mu A } \left\{(1+\mu A)\left[\frac{E_{2}\left[\left(T_{N}+\mu B\right) \sec \alpha\right]}{\sec \alpha}-\frac{E_{2}\left[\left(T_{N}+\mu B\right) \sec \beta\right]}{\sec \beta}\right]\right.\right. \\
& \left.+\left(T_{N}+\mu B\right)\left[E_{1}\left[\left(T_{N}+\mu B\right) \sec \alpha\right]-E_{1}\left[\left(T_{N}+\mu B\right) \sec \beta\right]\right]\right\} \\
& -e^{1-\mu G}\left\{(1+\mu G)\left[\frac{E_{2}\left[\left(T_{N}+\mu H\right) \sec \alpha\right]}{\sec \alpha}-\frac{E_{2}\left[\left(T_{N}+\mu H\right) \sec \beta\right]}{\sec \beta}\right]\right.
\end{aligned}
$$$$
\left.\left.+\left(T_{N}+\mu H\right)\left[E_{1}\left[\left(T_{N}+\mu G\right) \sec \alpha\right]-E_{1}\left[\left(T_{N}+\mu G\right) \sec \beta\right]\right]\right\}\right\} .
$$

Integration by parts gives rise to the following relationship allowing evaluation of $\mathrm{F}_{\mathrm{II}}$ in terms of $\mathrm{E}_{1}(\mathrm{X})$.

$$
E_{2}(X)=e^{-X}-E_{1}(X)
$$


VI. COATED PARTICLE MODEL

The costed particle model representation is as follows

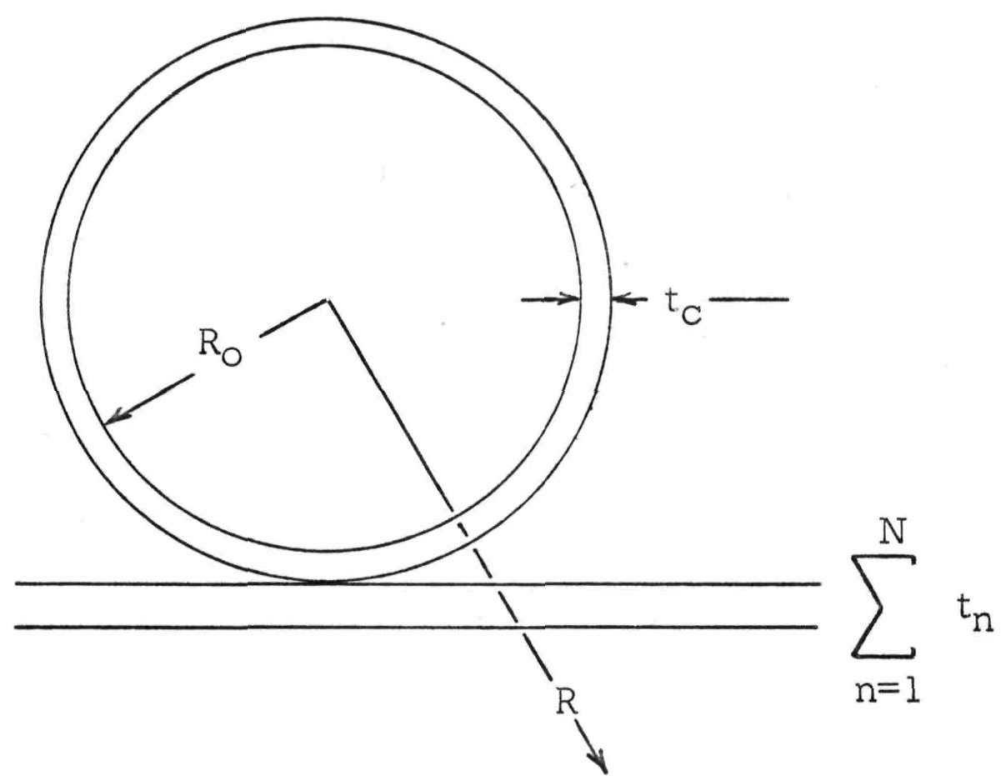

Recalling the cose distribution, $J(R, \theta)$, for $X(R, \theta) \leq C$

$$
J_{l}(R, \theta)=D_{S}\left(\frac{R_{0}}{R}\right)^{2}\left[C-X(R, \theta) e^{l-X(R, \theta) / C}+X(R, \theta) e^{l-X(R, \theta)}\right]
$$

for $X(R, \theta)>C$

$$
J_{2}(R, \theta)=D_{S}\left(\frac{R_{0}}{R}\right)^{2}\left[X(R, \theta) e^{l-X(R, \theta)}\right]
$$

where

$$
\begin{aligned}
& X(R, \theta)=\mu R+\mu_{C} t_{C}+T_{N} \sec \theta \\
& T_{N}=\left[\sum_{n=1}^{N} \mu_{n} t_{n}-\mu\left(\sum_{n=1}^{N} t_{n}+t_{C}+R_{0}\right)\right]
\end{aligned}
$$


Equating $\ell(\theta)=R(\theta)$, gives

$$
\theta_{I I}=\sec ^{-1}\left[\frac{R_{I}-\left(R_{O}+t_{C}\right)}{S_{N}-\left(R_{O}+t_{C}\right)}\right]
$$

and

$$
R_{I I}=S_{N}\left[\frac{R_{I}-\left(R_{O}+t_{C}\right)}{S_{N}-\left(R_{O}+t_{C}\right)}\right]
$$

A radial distance (measured from the particle center)

$$
R_{k}>\left[R_{0}+t_{C}+\sum_{n=1}^{N} t_{n}\right]
$$

may be specified for an integration limit to give

$$
\theta_{k}=\cos ^{-1}\left(\frac{S_{N}}{R_{k}}\right)
$$

For $\mathrm{R}_{\mathrm{k}}>\mathrm{R}_{\mathrm{I}}$, the angle of intersection, $\theta_{\mathrm{kx}}$ is

$$
\theta_{\mathrm{kx}}=\sec ^{-1}\left[\left(\frac{\mathrm{R}_{\mathrm{k}}-\mathrm{R}_{\mathrm{I}}}{\mathrm{R}_{\mathrm{O}}-\mathrm{t}_{\mathrm{c}}}\right)+1\right]
$$


Integration of $\mathrm{dJ}_{1}$ and $\mathrm{dJ}_{2}$ is carried out in the same manner as given in Section $V$ above, i.e., for

$$
\begin{gathered}
d_{I}(R, \theta)=D_{S} R_{0} 2 \pi\left[X(R, \theta) e^{1-C}-1+C\right] \sin \theta d \theta d R \\
F_{I C}=2 \pi D_{S} R_{0}^{2} \int_{\alpha}^{\beta} d \theta \int_{f(\theta)}^{g(\theta)}\left[\left(\mu R+\mu_{C} t_{C}+T_{N} \sec \theta\right)\left(e^{1-C}-1\right)+C\right] \sin \theta d R
\end{gathered}
$$

Comparison of the integral above for $F_{I C}$ with that of $F_{I}$ in Section $V$ above identifies the " $\mathrm{C}$ " term in $F_{I}$ with

$$
\left[\left(e^{1-C}-1\right) \mu_{C} t_{C}+C\right] \text {, here in } F_{I C^{\prime}} \text {; }
$$

and accordingly $F_{I C}$ (for the coat case) can be written as 


$$
\begin{aligned}
F_{I C}= & 2 \pi D_{S} R_{0}^{2}\left\{\left[\frac{\mu}{2}\left(G^{2}-A^{2}\right)\left(e^{1-C}-1\right)+\left[\left(e^{1-C}-1\right) \mu_{C} t_{C}+C\right](G-A)\right](\cos \alpha-\cos \beta)\right. \\
& +\left\{\left(e^{1-C}-C\right)\left[\mu(H G-A B)+T_{N}(G-A)\right]\right. \\
& \left.+\left[\left(e^{1-C}-1\right) \mu_{C} t_{C}+C\right](H-B)\right\} \ln \left|\frac{\cos \alpha}{\cos \beta}\right| \\
& \left.+\left[T_{N}(H-B)+\frac{\mu}{2}\left(H^{2}-B^{2}\right)\right]\left[\frac{1}{\cos \beta}-\frac{1}{\cos \alpha}\right]\right\}
\end{aligned}
$$

Integration of $\mathrm{dJ}_{2}$, given by

$$
d J_{2}(R, \theta)=D_{S} R_{0}^{2} 2 \pi\left[X(R, \theta) e^{1-X(R, \theta)}\right] \sin \theta d \theta d R
$$

gives

$$
F_{I I C}=e^{-\mu_{C} t_{C}} F_{I I}+2 \pi D_{S} R_{C}-\mu_{C} t_{C} \int_{\alpha(\theta)}^{\beta} d \theta \int_{C}^{g(\theta)} \mu_{C} t_{C} e^{-\left(\mu R+T_{N} \sec \theta\right)} \sin \theta d R
$$


First consider:

$$
\begin{aligned}
& \int_{\alpha}^{\beta} d \theta \int_{f(\theta)}^{g(\theta)} e^{-\left(\mu R+T_{N} \sec \theta\right)} \sin \theta d R \\
& \int_{f(\theta)}^{g(\theta)} e^{-\mu R} d R=\frac{1}{\mu}\left[e^{-\mu f(\theta)}-e^{\mu g(\theta)}\right]
\end{aligned}
$$

where

$$
\begin{aligned}
& f(\theta)=A+B \sec \theta \\
& g(\theta)=G+H \sec \theta
\end{aligned}
$$

Rewritting:

$$
\int_{f(\theta)}^{g(\theta)} e^{-\mu R} d R=\frac{1}{\mu}\left[e^{-\mu A} e^{-\mu B \sec \sigma}-e^{-\mu G} \cdot e^{-\mu H \sec \delta}\right]
$$

The $\theta$ integration is

$$
\begin{gathered}
\int_{\alpha}^{\beta} \frac{1}{\mu}[] e^{-T_{N} \sec \theta} \sin \theta d \theta \\
=\frac{e^{-\mu A}}{\mu} \int_{\alpha}^{\beta} e^{-\left(\mu B+T_{N}\right)} \cdot \frac{-\mu G}{\mu} \int_{\alpha}^{\beta} e^{-\left(\mu \mathrm{H}+T_{N}\right) \sec \theta} \sin \theta d \theta
\end{gathered}
$$




$$
\int_{\alpha}^{\beta} e^{-\left(\mu B+T_{N}\right) \sec \theta} \sin d \theta=\left(\mu B+T_{N}\right) \int_{\left(\mu B+T_{N}\right) \sec \alpha}^{\left(H B+T_{N}\right) \sec \beta} \frac{e^{-u}}{u^{2}} d u
$$

$$
=\frac{E_{2}\left[\left(\mu B+T_{N}\right) \sec \alpha\right]}{\sec \alpha}-\frac{E_{2}\left[\left(\mu B+T_{N}\right) \sec \beta\right]}{\sec \beta}
$$

The integral,

$$
\int_{\alpha}^{\beta} e^{-\left(\mu G+T_{N}\right) \sec \theta} \sin \theta d \theta
$$

has the same form as that above, so that FII $_{\text {may be written as }}$

$$
\begin{aligned}
F_{I I C}= & e^{-\mu_{C} t_{C}} F_{I I}+\frac{2 \pi D_{S} R_{0}^{2} e^{-\mu_{C} t_{C}}}{\mu}\left\{\left(\mu B+T_{N}\right) e^{1-\mu A}\right. \\
& x\left[\frac{E_{2}\left[\left(\mu B+T_{N}\right) \sec \alpha\right]}{\sec \alpha}-\frac{E_{2}\left[\left(\mu B+T_{N}\right) \sec \beta\right]}{\sec \beta}\right]-\left(\mu H+T_{N}\right) e^{1-\mu G} \\
& \left.x\left[\frac{E_{2}\left[\left(\mu H+T_{N}\right) \sec \alpha\right]}{\sec \alpha}-\frac{E_{2}[(\mu H+N) \sec \beta]}{\sec \beta}\right]\right\}
\end{aligned}
$$


When

$$
\begin{gathered}
\mu_{C} t_{C}<1, \\
F_{I C}=e^{-\mu_{C} t_{C}} F_{I} \\
F_{I I C}=e^{-\mu_{C} t_{C}} F_{I I}
\end{gathered}
$$

where $F_{I}$ and $F_{I I}$ are developed above in Section $V$. 


\section{PROGRAM EQUATIONS AND INPUT INFORMATION (PRELIMINARY)}

A. INPUT

$\mathrm{R}_{\mathrm{O}}$ - particle radius, (cm)

$\rho_{\mathrm{S}}-$ particle density, $\left(\mathrm{gm} / \mathrm{cm}^{2}\right)$

$E_{i}$ - upper limit of beta energy group, i, (Mev) $i=1,10$ max.

$E_{i}$ - average value of beta energy group, $i,(\mathrm{Mev}) \mathrm{i}=1,10 \mathrm{max}$.

$\mathrm{S}_{i}$ - source strength of group i beta, (beta; sec) $i=1,10 \mathrm{max}$

$R$ - vector distance to dose point, (cm) 10 max.

$\theta$ - polar angle measured from surface normal, (deg) 10 max.

$t_{n}$ - nth absorber thickness, $(\mathrm{cm}) \mathrm{n}=1,5 \max$.

$\mu_{n}-n$th abosrber absorption coefficient, $(\mathrm{cm})^{-1}, \mathrm{n}=1,5 \max$.

$\rho_{\mathrm{n}}$ - absorber density for nth absorber(s) for which $\mu_{\mathrm{n}}$ are

- to be calculated, $\mathrm{gm} / \mathrm{cm}^{3}$ (optional), $\mathrm{n}=1,5 \mathrm{max}$.

$t_{C}$ - particle coating thickness, $(\mathrm{cm})$

$\mu_{\mathrm{C}}$ - absorption coefficient for particle coating $\left(\mathrm{cm}^{-1}\right)$

$R_{k}$ - boundary limit(s) of integration, $(\mathrm{cm}) \mathrm{k}=1,6 \max$.

B. SURFACE DOSE

If $\frac{1}{\mu_{S i}} \geq 2 R_{0}$

$$
D_{1 S i}=\frac{2 \pi K_{i}}{\mu_{S i}}\left[1-\frac{1}{2 \mu_{S i} R_{0}}+\frac{e^{-2 \mu_{S i} R_{O}}}{2 \mu_{S i} R_{O}}\right] \mathrm{rad} / \mathrm{hr}
$$




$$
\begin{aligned}
& \text { If } \frac{1}{\mu_{\text {Si }}}<2 R_{0} \\
& D_{2 s i}=\frac{2 \pi K_{i}}{\mu_{\mathrm{Si}}}\left[\frac{\mathrm{e}\left(2 \mu_{\mathrm{Si}} \mathrm{R}_{\mathrm{O}}-1\right)+2 \mu_{\mathrm{Si}} \mathrm{R}_{\mathrm{O}}-3}{2 e \mu_{\mathrm{Si}} \mathrm{R}_{\mathrm{O}}}\right. \\
& \left.+\left(1+\frac{1}{\mu_{\mathrm{Si}} \mathrm{R}_{\mathrm{O}}}\right) e^{-2 \mu_{\mathrm{Si}} \mathrm{R}_{\mathrm{O}}}\right] \mathrm{rad} / \mathrm{hr} \\
& K_{i}=4.6 \times 10^{-6} \frac{\mathrm{Si}}{\mathrm{V}} \quad E_{i} \nu_{i} \alpha_{i} \\
& V=\frac{4}{3} \pi R_{0}^{3} \\
& \nu_{i}=\frac{18.6}{\left(E_{i}-0.036\right)^{1.37}} \\
& \alpha_{i}=\left[3 C_{i}^{2}-\left(C_{i}^{2}-1\right) e\right]-1 \\
& C_{i}=3.11 \mathrm{e}^{-0.55 E_{i}} \\
& \mu_{\mathrm{Si}}=\frac{17 \rho_{\mathrm{S}}}{E_{i}} \mathrm{f}_{\mathrm{i}}
\end{aligned}
$$




$$
\begin{array}{rlrl}
f_{i} & =4.5 E_{i}+0.465 & 0.01 \leq E_{1} \leq 0.02 \\
& =2.0 E_{i}+515 & 0.02<E_{1} \leq 0.035 \\
& =0.731 E_{i}+0.5594 & & 0.035<E_{i} \leq 0.1 \\
& =0.2825 E_{i}+0.60425 & & 0.1<E_{i} \leq 0.3 \\
& =0.155 E_{i}+0.6425 & & 0.3<E_{1} \leq 0.5 \\
& =0.12 E_{i}+0.66 & & \\
& =0.78 e^{0.0962 E_{i}} & & 1.0<E_{i} \leq 2.0 \\
& =0.86 e^{0.0742 E_{i}} & & 2.0<E_{i} \leq 4.0 \\
& =0.996 e^{0.48 E_{i}} & & 4.0<E_{i} \leq 8.0
\end{array}
$$

( $f_{i}$ is a $U_{C}$ set based on lead and aluminum ratios.)

C. DOSE DISTRIBUTTON

$$
\begin{aligned}
& \text { If } X_{i}(R, \theta) \leq C_{i} \\
& \qquad \begin{aligned}
J_{l i}(R, \theta)=\frac{D_{S i} R_{O}^{2}}{R^{2}}[ & C_{i}-X_{i}(R, \theta) e^{l-X_{i}(R, \theta) / C_{i}} \\
& \left.+X_{i}(R, \theta) e^{l-X_{i}(R, \theta)}\right] \mathrm{rad} / \mathrm{hr}
\end{aligned}
\end{aligned}
$$




$$
\begin{aligned}
& \text { If } X_{i}(R, \theta)>C_{i}
\end{aligned}
$$

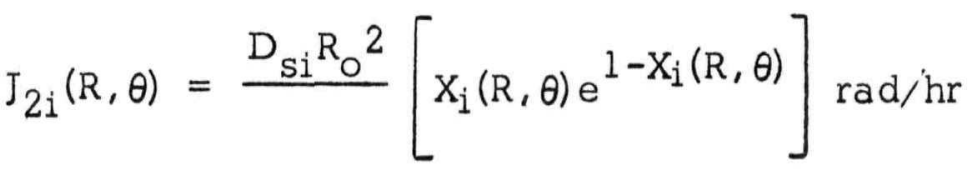

$$
\begin{aligned}
& X_{i}(R, \theta)=\mu_{i} R+T_{N i} \sec \theta \\
& \mathrm{T}_{\mathrm{Ni}}\left[\sum_{\mathrm{n}=1}^{\mathrm{N}} \mu_{\mathrm{n} i} \mathrm{t}_{\mathrm{n}}-\mu_{\mathrm{i}}\left(\mathrm{R}_{\mathrm{O}}+\sum_{\mathrm{n}=1}^{\mathrm{N}} \mathrm{t}_{\mathrm{n}}\right)\right] \\
& \mu_{n i}=\frac{18.6 \rho_{n}}{\left(E_{i}-0.036\right)^{1.37}} \mathrm{~cm}^{-1} \\
& \mu_{i}=\frac{18.6}{\left(E_{i}-0.036\right)^{1.37}} \mathrm{~cm}^{-1}
\end{aligned}
$$

D. INTEGRAL DOSE AND AY

$$
\begin{aligned}
& \text { Integral Dose } \\
& \begin{aligned}
D_{k+1, k, i}=D_{k+1, i} & -D_{k, i}(g m-r a d) \\
& -30-
\end{aligned}
\end{aligned}
$$


Average Dose

$$
\begin{gathered}
D_{k+1, k, i}=\frac{D_{k+1, k, i}}{V_{k+1}-V_{k}}(\text { rad }) \\
\left.V_{k}=\frac{2 \pi}{3}\left[\frac{S_{N}{ }^{3}}{2} \tan ^{3} \theta, \cdot 3, \theta-1\right)\right]\left(\mathrm{cm}^{3}\right)
\end{gathered}
$$

Case Number Condition

$$
\begin{aligned}
& \text { I } \\
& \text { If } R_{k} \leq R_{1 i}, D_{k i}=F_{11} \\
& 2 \\
& \text { If } R_{I i}<R_{k} \leq R_{I I}, D_{k i}=F_{I 1 i}+F_{I 2 i}+F_{I I I} \\
& 3 \\
& \text { If } R_{k}>R_{I I i}, D_{k}=F_{11}+F_{1121}+F_{I 3 i} \\
& \mathrm{R}_{\mathrm{Ii}}=\frac{\mathrm{C}_{\mathrm{i}}-\mathrm{T}_{\mathrm{N}}}{\mu_{\mathrm{i}}} \\
& \theta_{\mathrm{Ii}}=\cos ^{-1}\left[\frac{\mathrm{S}_{\mathrm{N}}}{\mathrm{R}_{\mathrm{Ii}}}\right] \\
& s_{N}=R_{0}+\sum_{n=1}^{N} t_{n}
\end{aligned}
$$




$$
\begin{gathered}
\theta_{I I i}=\sec ^{-1}\left[\frac{R_{I i}-R_{O}}{S_{N}-R_{O}}\right] \\
R_{I I i}=\frac{S_{N}\left(R_{I i}-R_{O}\right)}{S_{N}-R_{O}} \\
\theta_{k}=\cos ^{-1}\left[\frac{S_{N}}{R_{k}}\right] \\
\theta_{k i}=\sec ^{-1}\left[\frac{R_{k}+R_{0}-R_{I i}}{R_{O}}\right] \\
F_{I i}=2 \pi D_{S i} R_{0}\left\{\left[\frac{\mu}{2}\left(G^{2}-A^{2}\right)\left(e^{1-C}-1\right)+C(G-A)\right](\cos \alpha-\cos \beta)\right. \\
+\left[\left(e^{1-C}-1\right)\left[\mu(H G-A B)+T_{N}(G-A)\right]+C(H-B)\right] \ln \left|\frac{\cos \alpha}{\cos B}\right| \\
\left.+\left[T_{N}(H-B)+\frac{\mu}{2}\left(H^{2}-B^{2}\right)\right]\left[\frac{1}{\cos \beta}-\frac{1}{\cos \alpha}\right]\right\}
\end{gathered}
$$




$$
F_{I I i}=\frac{2 \pi D_{S i} R_{O}^{2}}{\mu_{i}}\left\{e ^ { 1 - \mu A } \left[(1+\mu A)\left(\frac{E_{2}\left[\left(T_{N}+\mu B\right) \sec \alpha\right]}{\sec \alpha}-\frac{E_{2}\left[\left(T_{N}+\mu B\right) \sec \beta\right]}{\sec \beta}\right)\right.\right.
$$

$$
\begin{aligned}
& \left.+\left(\mathrm{T}_{N}+\mu \mathrm{B}\right)\left[E_{1}\left(\left(\mathrm{~T}_{\mathrm{N}}+\mu \mathrm{B}\right) \sec \alpha\right)-E_{1}\left(\left(\mathrm{~T}_{N}+\mu \mathrm{B}\right) \sec \beta\right)\right]\right] \\
& -e^{1-\mu \mathrm{G}}\left[(1+\mu \mathrm{G})\left(\frac{E_{2}\left[\left(\mathrm{~T}_{N}+\mu \mathrm{H}\right) \sec \alpha\right]}{\sec \alpha}-\frac{E_{2}\left[\left(\mathrm{~T}_{N}+\mu \mathrm{H}\right) \sec \beta\right]}{\sec \beta}\right)\right.
\end{aligned}
$$

$$
\left.\left.\left.+\left(\mathrm{T}_{N}+\mu \mathrm{H}\right)\left[\mathrm{E}_{1}\left(\left(\mathrm{~T}_{\mathrm{N}}+\mu \mathrm{G}\right) \sec \alpha\right)-\mathrm{E}_{1}\left(\mathrm{~T}_{\mathrm{N}}+\mu \mathrm{G}\right) \sec \beta\right)\right]\right]\right\}
$$

$$
E_{2}(x)=e^{-x}-E_{1}(x)
$$

Polynomial approximation for $E_{1}(x)$ will include two or three other equations as a subroutine computation. 
PARAMETER IDENTIFICATION FOR F $\mathrm{F}_{\mathrm{II}}$ AND F FII FUNCTION TYPES

\begin{tabular}{|c|c|c|c|c|c|c|c|}
\hline CASE NUMBER & FUNCTION & $\mathrm{A}$ & B & $G$ & $\mathrm{H}$ & $\alpha$ & $\beta$ \\
\hline 1 & $F_{[1 i}$ & 0 & $\mathrm{~S}_{\mathrm{N}}$ & $\mathrm{R}_{\mathrm{k}}$ & 0 & 0 & $\theta_{k}$ \\
\hline 2 & $\mathrm{~F}_{\mathrm{Ili}}$ & 0 & $\mathrm{~S}_{\mathrm{N}}$ & $\left(R_{1},-R_{O}\right)$ & $\mathrm{R}_{\mathrm{O}}$ & 0 & $\theta_{\mathrm{ki}}$ \\
\hline 2 & $\mathrm{~F}_{\mathrm{I} 2 \mathrm{i}}$ & 0 & $s_{N}$ & $R_{k}$ & 0 & $\theta_{\mathrm{ki}}$ & $\theta_{k}$ \\
\hline 2. & $\mathrm{~F}_{\mathrm{III} i}$ & $\left(\mathrm{R}_{\mathrm{Ii}}-\mathrm{R}_{\mathrm{O}}\right)$ & $\mathrm{R}_{0}$ & $\mathrm{R}_{\mathrm{k}}$ & 0 & 0 & $\theta_{\mathrm{ki}}$ \\
\hline 3 & $\mathrm{~F}_{\mathrm{Ili}}$ & 0 & $\mathrm{~S}_{\mathrm{N}}$ & $\left(R_{I i}-R_{0}\right)$ & $\mathrm{R}_{\mathrm{O}}$ & 0 & $\theta_{I I i}$ \\
\hline 3 & $\mathrm{~F}_{I I l i}$ & $\left(R_{I 1}-R_{O}\right)$ & $\mathrm{R}_{\mathrm{O}}$ & $\mathrm{R}_{\mathrm{II} i}$ & 0 & 0 & $\theta_{\text {IIi }}$ \\
\hline 3 & $\mathrm{~F}_{\mathrm{II} 21}$ & $\mathrm{R}_{\mathrm{II} i}$ & 0 & $\mathrm{R}_{\mathrm{k}}$ & 0 & 0 & $\theta_{\mathrm{IIi}}$ \\
\hline 3 & $\mathrm{~F}_{\mathrm{I} 3 i}$ & 0 & $\mathrm{~S}_{\mathrm{N}}$ & $\mathrm{R}_{\mathrm{k}}$ & 0 & $\theta_{I I i}$ & $\theta_{k}$ \\
\hline
\end{tabular}

